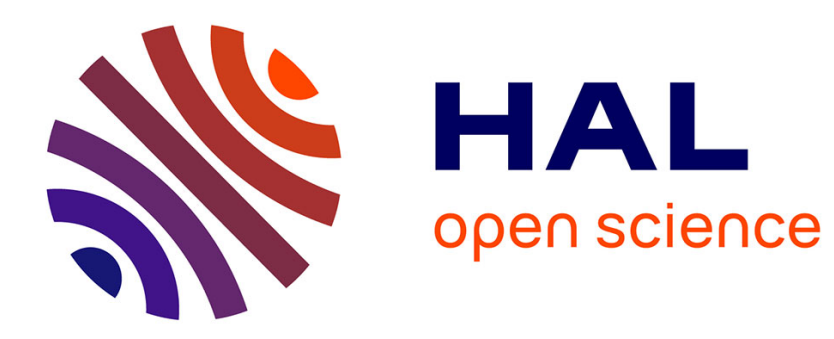

\title{
Does Performance-Sensitive Debt mitigate Debt Overhang?
}

Alain Bensoussan, Benoit Chevalier-Roignant, Alejandro Rivera

\section{To cite this version:}

Alain Bensoussan, Benoit Chevalier-Roignant, Alejandro Rivera. Does Performance-Sensitive Debt mitigate Debt Overhang?. Journal of Economic Dynamics and Control, 2021, 131. hal-03364891

\section{HAL Id: hal-03364891 \\ https://hal.science/hal-03364891}

Submitted on 5 Oct 2021

HAL is a multi-disciplinary open access archive for the deposit and dissemination of scientific research documents, whether they are published or not. The documents may come from teaching and research institutions in France or abroad, or from public or private research centers.
L'archive ouverte pluridisciplinaire HAL, est destinée au dépôt et à la diffusion de documents scientifiques de niveau recherche, publiés ou non, émanant des établissements d'enseignement et de recherche français ou étrangers, des laboratoires publics ou privés. 


\section{Journal Pre-proof}

Does Performance-Sensitive Debt mitigate Debt Overhang?

Alain Bensoussan, Benoît Chevalier-Roignant, Alejandro Rivera

PII: S0165-1889(21)00138-X

DOI: https://doi.org/10.1016/j.jedc.2021.104203

Reference: DYNCON 104203

To appear in: Journal of Economic Dynamics \& Control

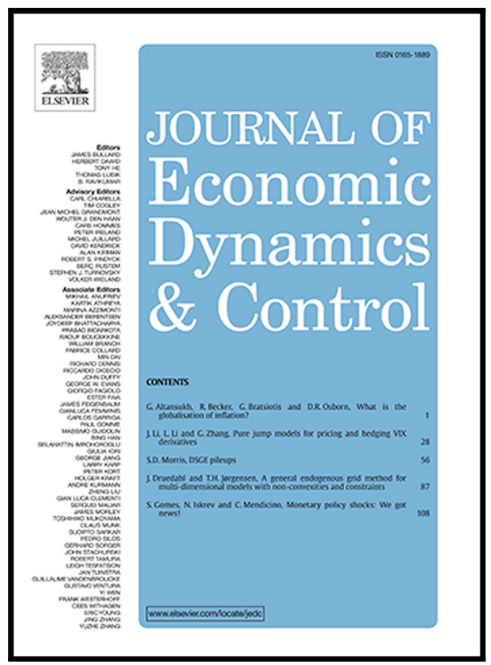

Received date: $\quad 15$ June 2020

Revised date: $\quad 20$ July 2021

Accepted date: $\quad 25$ July 2021

Please cite this article as: Alain Bensoussan, Benoît Chevalier-Roignant, Alejandro Rivera, Does Performance-Sensitive Debt mitigate Debt Overhang?, Journal of Economic Dynamics \& Control (2021), doi: https://doi.org/10.1016/j.jedc.2021.104203

This is a PDF file of an article that has undergone enhancements after acceptance, such as the addition of a cover page and metadata, and formatting for readability, but it is not yet the definitive version of record. This version will undergo additional copyediting, typesetting and review before it is published in its final form, but we are providing this version to give early visibility of the article. Please note that, during the production process, errors may be discovered which could affect the content, and all legal disclaimers that apply to the journal pertain.

(C) 2021 Published by Elsevier B.V. 


\title{
Does Performance-Sensitive Debt mitigate Debt Overhang?*
}

\author{
Alain Bensoussan \\ University of Texas at Dallas \\ City University of Hong Kong \\ Benoît Chevalier-Roignant \\ Cranfield University \\ Alejandro Rivera \\ University of Texas at Dallas \\ University of California at Berkeley
}

July 8, 2021

\footnotetext{
${ }^{*}$ Corresponding author: Alejandro Rivera (alejorivera1@berkeley.edu). The authors would like to thank Karan Bhanot, Gilles Chemla, Ted Day, Christoph Flath, Palani-Rajan Kadapakkam, Nicos Koussis, Maria Loumioti, Gustavo Manso, Jean-Marie Meier, Eduardo Schwartz, Gordon Sick, Sheridan Titman, Andrianos Tsekrekos, Lenos Trigeorgis, John Wald, Michael Wittry, Han Xia, Steven Xiao, Harold Huibing Zhang, Feng Zhao, participants at the international real options conference in Dusseldorf, INFORMS annual meeting in Phoenix and the second RCEA Warsaw Macro-Finance Conference as well as participants at research seminars in Athens University of Economics and Business, Paris Financial Management Conference 2019, University of Texas at San Antonio, CASS Business School, Cranfield School of Management, the University of Texas at Dallas, and the University of Bielefeld. This paper was previously circulated as "Capacity Expansion Options and Optimal Performance-Sensitive Debt". Research supported by the National Science Foundation under grant no. DMS-1612880, and grant no. DMS- 1905449, and by the SAR Hong Kong under grand no. RGC GRF 113033316. First Draft: April, 2019
} 


\section{Nomenclature}

$\begin{array}{ll}\text { Symbol } & \text { Interpretation } \\ \text { Primitives } x^{\gamma} \delta^{\epsilon} & \text { Operating cashflows } \\ \beta_{0}, \beta_{\gamma} & \text { PSD parameters } \\ k & \text { Cost per unit of extra capacity } \\ \mu, \sigma & \text { Drift and volatility parameters } \\ \alpha & \text { Bankrupcy cost } \\ \text { Decision } \nu & \text { Firm strategy } \\ \text { variables } \tau_{I} & \text { Investment time } \\ \xi & \text { Investment lump } \\ \tau_{D} & \text { Default time } \\ \text { Value } F & \text { Decisions on } \tau_{I}, \xi \text { and } \tau_{D} \\ \text { functions } \varphi & \text { Decision on } \tau_{D} \\ \Phi & \text { Obstacle for the optimal stopping problem } F \\ (\text { Free }) x_{0}(\cdot) & \text { Default's free boundary for the problem } F \\ \text { boundaries } x_{1}(\cdot) & \text { Default's free boundary for the problem } \varphi \\ \delta_{1}(\cdot) & \text { Inverse of } \bar{x}_{1}(\cdot) \\ \delta_{3}(x) \geq \delta^{\star} & \text { Local maximum of } \delta \mapsto \phi(x, \delta)=k \delta \text { for } x \geq x^{\star} \\ x_{3}(\delta) \geq x^{\star} & \text { Inverse of } \delta_{3}(\cdot) \\ x_{4}(\cdot) & \text { Lowest } x \text { value such that } g(x, \delta)<0 \text { for } x>x_{4}(\delta) \\ x_{5}(\cdot) & \text { Investment's free boundary for the problem } F \\ \text { Secondary } \pi & \text { Free cashflows to equity } \\ \text { parameters } \eta_{0}, \eta_{\gamma} \text { Perpetuity parameters depending on } \beta_{0}, \beta_{\gamma}, r, \mu, \sigma \text { and } \theta \\ \mathcal{Q}(\cdot) & \text { "Fundamental quadratic" depending on } r, \mu \text { and } \sigma \\ \gamma_{A}, \gamma_{B} & \text { Roots of the "fundamental quadratic" } \\ \lambda & \text { Constant depending on } r, \mu, \sigma, \beta_{0}, \beta_{\gamma}, \gamma \text { and } \theta \\ \rho & \text { Constant depending on } r, \mu, \sigma, \gamma \text { and } \epsilon \\ \text { Operators } \mathcal{L} & \text { Infinitesimal generator of the process }\left(X_{t} ; t \geq 0\right) \\ \partial_{y} & \text { First-order partial derivative (w.r.t. } y)\end{array}$




\title{
Does Performance-Sensitive Debt mitigate Debt Overhang?
}

\begin{abstract}
We model the expansion decision of a levered firm. Straight debt distorts both timing and scaling: the firm invests less and later than its all-equity financed counterpart. The inclusion of performance sensitivity in the debt contract mitigates such distortions. Moreover, performance sensitivity is consistent with firm value maximization within a standard trade-off theory of capital structure. As a result, our model rationalizes the widespread use of performance sensitive debt (PSD), especially amongst fast growth firms.
\end{abstract}

Keywords: Debt Overhang, Performance-Sensitive Debt, Capital Structure, Real Options. 


\section{Introduction}

This article studies the optimal exercise of real options with time and scale flexibility when the firm is financed with performance-sensitive debt (PSD). The issuance of hybrid debt instruments, such as PSD, has become popular as an alternative to straight debt, especially for corporate bank loans (see, e.g., Asquith, Beatty, and Weber, 2005; Manso, Strulovici, and Tchistyi, 2010). A PSD contract stipulates interest payments that are not constant, but depend on a measure of the borrower's performance. The focus in the literature has been so far on (i) pricing such PSD instruments and (ii) developing rationales for their use. A case in point where our setting would apply would be a pharmaceutical company that decides on when to open another laboratory and how large to build it, aware that the interest on the outstanding debt depends on the firm's Debt/EBITDA ratio. Asquith et al. (2005) detail Core Laboratories syndicated revolving loan performance-pricing grid. Moreover, it is known since Myers's (1977) paper that a firm financed with straight debt underinvests compared to its unlevered counterpart; this is because shareholders pay for the upfront cost of investment, but do not fully internalize its benefits (because of a debt overhang). The purpose of this article is to address the following set of interrelated questions: (a) What are the optimal default and capacity expansion policies for shareholders when the firm is financed with PSD? (b) To which extent can PSD mitigate the debt-overhang problem in the timing and scale of investment? (c) Can the widespread use of performance-pricing clauses in bank loans (documented by Asquith et al., 2005) be rationalized within a standard tradeoff theory of capital structure (see Kraus and Litzenberger, 1973)?

This paper answers these questions by modeling a firm partially financed with 'risk-compensating' PSD (Manso et al., 2010). Shareholders choose an optimal default policy (Leland, 1994) and decide on the exercise of a real option (Dixit and Pindyck, 1994; Trigeorgis, 1996). Optimal leverage and sensitivity of debt are jointly optimized in our setting. That is, we model a setting where the initial shareholders (e.g., entrepreneurs) decide on the best debt contract among a menu offered by their bank. Banks can offer straight debt, but they can also offer debt whose coupon payments depends on the firm's performance (PSD). We characterize how this financing choice depends on the available investment opportunities the firm has, which we model as expansion real options. 
We are particularly interested in the role played by PSD in mitigating debt overhang, and how such mitigating effect can rationalize the use of PSD by certain type of firms. To that end, we compute the equilibrium capital structure and investment decision that maximizes shareholder returns subject to the participation constraint of the banking sector.

The firm's profitability and scale determine its free cashflows to equity (FCFEs). The management can increase the firm's scale at a time of its choosing. As in Myers (1977), shareholders finance this expansion project. If the firm is financed with PSD, the management factors in the reduction in debt payments resulting from greater scale when deciding about an expansion.

The timeline is as follows. Ex ante, the initial owners decide on the firm's capital structure by specifying a debt amount and the performance sensitivity of its debt given a preexisting scale resulting from past investment decisions. That is, the initial shareholders decide which is the optimal debt contract that can be offered to them by the bank. Banks can offer straight debt, but they can also offer debt whose coupon payments depends on the firm's performance.

The optimal capital structure trades off (a) bankruptcy costs, (b) tax advantage of debt and (c) underinvestment induced by debt. Ex post, given outstanding debt, the management chooses the expansion \& default policy that maximizes shareholder value.

Our model helps us derive three novel insights. First, the expansion decision of a firm financed with straight debt is distorted (compared to the decision of its unlevered counterpart) in both timing and scaling: the former invests less and later. Our paper is the first to highlight such a distortionary effect in a unifying framework showcasing optimal timing and scaling of investment. ${ }^{1}$ Intuitively, shareholders finance the new project, yet do not fully internalize the benefits as debtholders capture some benefits in the event of bankruptcy. Consequently, the management will defer the option exercise until the benefits to shareholders are sufficiently large (in a sense that we shall specify explicitly). Moreover, because of debt overhang, the marginal benefit of investment to shareholders will always be lower than that of an unlevered firm, leading to a lower scale of investment.

Second, we show that PSD can mitigate the debt-induced distortions: the performance-sensitivity criterion can induce a firm to invest sooner and in a larger amount than a similar firm financed

\footnotetext{
${ }^{1}$ Hennessy (2004) shows underinvestment in a neoclassical investment framework without timing considerations. Mauer and Ott (2000) show investment delay in a real options framework with fixed scale.
} 
with straight debt. Because PSD rewards a firm with a larger scale with lower debt payments, the management will approve a growth plan financed by shareholders. Under straight debt, investment increases the size of the pie, but also increases the size of the slice accruing to debtholders, thereby constituting a transfer of wealth from shareholders to debtholders. By contrast, under PSD, debtholders receive lower debt payments after investment, while shareholders internalize a larger slice of the pie. It is therefore optimal for shareholders to invest earlier and more. ${ }^{2}$

Third, the initial shareholders may maximize total firm value by issuing PSD. Because PSD brings the firm's investment policy closer to the investment policy followed by an unlevered firm, total firm value is enhanced by introducing performance sensitivity. Our model provides a theory for optimal leverage and optimal sensitivity of debt, and rationalizes the extensive use of performance sensitive clauses in private debt contracts documented by Asquith, Beatty, and Weber (2005). ${ }^{3}$

The paper is organized as follows. Section 2 provides a review of the literature. Section 3 introduces the model and motivates the assumptions. Section 4.1 presents the benchmark model where the firm decides uniquely on the time of default. Section 4.2 elaborates on the decision on the expansion lump, while Section 4.3 discusses the timing decision. Section 5 justifies the use of PSD as a devise to mitigate the debt overhang.

\section{Literature Review}

Empirical studies documenting the prevalence of performance sensitive debt include Asquith et al. (2005), Manso et al. (2010), and Kjenstad, Su, and Xia (2018). Asquith et al. (2005) obtain commercial loan data from the Loan Pricing Corporation (LPC) database and focuses primarily on bank debt with long maturities. Of the bank loan sample, $41 \%$ ( $\$ 943 \mathrm{bn})$ contained a performancepricing component. This figure is consistent with Manso et al. (2010), who-based on bank loan data from Thomson Financial's SDC database - show that $40 \%$ of the loans have performancepricing provisions. Importantly, their finding that fast-growth firms are more likely to issue PSD

\footnotetext{
${ }^{2}$ Our results for the scale of investment are proven analytically in Corollary 1 . The results for the timing of investment are numerical, but robust to a wide range of parameter specifications.

${ }^{3}$ Other works rationalize the use of PSD, in particular Manso et al. (2010) based on the signaling theory, Tchistyi, Yermack, and Yun (2011) based on the shareholder wealth extraction theory, and Adam, Burg, Scheinert, and Streitz (2020) based on the theory of managerial overconfidence.
} 
is consistent with our model. Kjenstad et al. (2018) study the interplay between product market competition and performance-pricing provisions. They posit that PSD and product market competition act as substitutes to mitigate shareholder-debtholder conflicts and empirically document that firms operating in markets with low levels of product market competition are more likely to have performance-pricing clauses.

Despite being used widely in private debt contracts, only a few theory papers study performance sensitivity. Manso et al. (2010) were the first to model PSD in the credit-risk literature. In a model without investment, they showed that PSD reduces total firm value (compared to straight debt) because it leads to earlier default. But they rationalize the existence of PSD as a signaling device when borrowers have heterogeneous types (adverse selection). Our contribution is complementary as we discuss yet another rationale: PSD helps align the interests of debtholders and shareholders when a firm decides on its investment policy, an effect akin to mitigating shareholder moral hazard on the optimal investment decision.

Other contributions in this literature stream include Manso (2013) who shows that when a firm's interest payments depend on its credit rating, there exists a soft-rating and a tough-rating equilibrium featuring, respectively, low and high default rates. Tchistyi, Yermack, and Yun (2011) focus on the optimal sensitivity of debt when managers are compensated with stock options. They provide theoretical and empirical evidence that a more generous granting of stock options increases the "vega" of the managers" compensation package, thereby incentivizing them to increase risk on equity via PSD. Following Sarkar and Zhang (2015), PSD can mitigate the excessive delay in real option exercise induced by straight debt. Our paper expands their analysis by simultaneously studying the distortionary effect of debt on the timing and scale of investment as well as by providing a theory for the joint determination of leverage and performance sensitivity of debt.

Very few real options papers discuss decisions on firm scale according to a recent survey by Trigeorgis and Tsekrekos (2018). Dangl (1999) characterizes the optimal exercise of one expansion option with scale flexibility. Bensoussan, Chevalier-Roignant, and Rivera (2019) consider a more general problem of capacity expansion under fixed running costs, while Bensoussan and Chevalier-Roignant (2018) study the sequential exercise of expansion options. The early literature ignored financing considerations. More recently, several authors (see Mauer and Sarkar, 2005; Sundaresan and Wang, 
2007; Shibata and Nishihara, 2015) investigate the decision of an unlevered firm to finance a real option's exercise cost with debt. ${ }^{4}$ Our paper fills a gap in the literature by characterizing the optimal exercise policy of a firm financed with PSD to expand its scale of production and by explaining how the issuance of a performance-sensitive debt instrument helps reduce agency costs by mitigating the debt-overhang problem in a dynamic setting.

A growing literature examines the relation between different types of contracts and the agency cost of debt. Hackbarth and Mauer (2012) study the optimal priority structure of debt that minimizes the debt overhang cost in a real options framework. Diamond and He (2014) show that short-term debt alleviates the debt-overhang problem. Moreover, holding debt value constant, their model implies an interior solution for the optimal maturity of debt. ${ }^{5}$ Bhanot and Mello (2006) study the role of credit rating triggers on shareholder incentives to take risk. They conclude that such triggers (that force shareholders to buy back debt after poor performance) can mitigate the risk-shifting problem as long as the debt is paid for with freshly injected equity. ${ }^{6}$

Finally, our paper also relates to the literature calibrating the extent of debt overhang. Mello and Parsons (1992) were the first to quantify the magnitude of the debt overhang problem. They note that the magnitude of the agency cost of debt varies with its deflator (e.g., debt or equity value, levered or unlevered firm value). They calculate this agency cost is $0.8 \%$ of firm value but $4.3 \%$ of debt value. Moyen (2007) measures a larger overhang cost with both long and short-term debt. For instance, with short-term debt, she computes the debt overhang cost add up to $5.12 \%$ of firm value. More recently, Chen and Manso (2017) compute how debt-overhang costs depend on business cycle risks. In their benchmark case, the debt overhang costs for a low leverage firm is less than $0.5 \%$ of the total firm yalue without macroeconomic risk, while these costs are as large as $2.7 \%$ or $3.6 \%$

\footnotetext{
${ }^{4}$ Recent contributions to the real option literature in non-standard settings also include Miao and Wang (2007), who characterize optimal option exercise for a risk-averse entrepreneur under incomplete markets. Nishimura and Ozaki (2007) and Miao and Wang (2011) study the optimal exercise of real option under ambiguity aversion. Bolton, Wang, and Yang (2014), and Hugonnier, Malamud, and Morellec (2014) study real options within a liquidity management framework. Gryglewicz, Hartman-Glaser, and Zheng, and Philippon and Sannikov (2007) characterize real option exercise under managerial moral hazard. Lambrecht and Myers (2008) characterize optimal investment decisions when managers maximize the present value of their future compensation.

${ }^{5}$ Other papers focusing on the optimal maturity of debt include Della Seta, Morellec, and Zucchi (2020); Titman and Tsyplakov (2007); He and Xiong (2012), and He and Milbradt (2014).

${ }^{6}$ A large literature studies shareholder-debtholder conflicts including Edmans and Liu (2010); Jensen and Meckling (1976); Myers (1977); Hackbarth, Rivera, and Wong (2018); Hennessy (2004); Mello and Parsons (1992); Leland (1998); Ericsson (2000); Kumar and Yerramilli (2017); He (2011); Morellec (2001); Parrino and Weisbach (1999); Rivera (2020); Schwartz (1982); Whited (1992); Wittry (2021) among others.
} 
in booms and recessions, respectively, in the presence of macroeconomic risk. Our contribution relative to this literature is to show that the cost of debt-overhang encompasses a simultaneous distortion of the scale and timing of investment, in relation to the first-best investment benchmark.

\section{Model}

We consider a continuous-time setting where a firm earns a running operating cashflow $x \sqrt{\delta}$ which depends on its scale $\delta \geq \delta^{*}>0$ and profitability $x>0 .{ }^{7}$ On the probability space $(\Omega, \mathscr{F}, \mathbb{P})$, we consider a (standard) Brownian motion $Z: \Omega \times \mathbb{R}_{+} \rightarrow \mathbb{R}$, which generates a filtration $\mathbb{F}=(\mathscr{F} ; t \geq 0)$. The firm's profitability $X: \Omega \times \mathbb{R}_{+} \rightarrow \mathbb{R}_{+}$follows a geometric Brownian motion:

$$
\begin{cases}X_{0}=x, & \mathbb{P} \text {-a.s. } \\ \mathrm{d} X_{t}=\mu X_{t} \mathrm{~d} t+\sigma X_{t} \mathrm{~d} Z_{t}, & \forall t>0 .\end{cases}
$$

We assume $r>\mu>\sigma^{2} / 2$ and $\sigma>0$ as usual. The expectation $\mathbb{E}_{x, \delta}$ is conditional on the initial values for the states $x$ and $\delta$. The initial firm scale $\delta$ is a result of the firm's past investment history, possibly zero.

At the outset, the firm finances itself via a mix of equity and PSD. Debt contracts often stipulate negative covenants which prevent the issue of new debt until the outstanding debt has matured. In this paper, we focus on such cases, so the issuance of new debt at the expansion time is precluded. We consider a "risk-compensating" PSD, i.e., a debt instrument that pays higher interest payments when performance worsens. We here proxy the firm's performance by its operating cashflows (rather than, say, its credit rating or a balance sheet ratio). Following the terminology introduced in Manso et al. (2010), for tractability reasons we specifically assume a linear PSD for which the interest paid is of the form $\beta_{0}-\beta_{1} x \sqrt{\delta}$ with $\beta_{0}, \beta_{1} \geq 0$. By construction, the interest payment can be negative for large values of $x$ or $\delta$. However, in our numerical analyses, we calibrate the debt parameter $\beta_{1}$ such that the interest payments become negative only at very large values of $x$, an event which occurs in the remote future. To focus on the effects induced by debt financing, we abstract away

\footnotetext{
${ }^{7}$ For tractability reasons we require the initial scale to be larger than the constant $\delta^{*}$, specified below. As a consequence our model is most applicable to firms with a non-trivial existing capacity.
} 
from any other fixed and variable costs. Firms pay corporate taxes at a rate $\theta \in(0,1)$. As in Leland (1994), the free cashflow to equity (FCFE) is

$$
\pi(x, \delta):=x \sqrt{\delta}-(1-\theta)\left(\beta_{0}-\beta_{1} x \sqrt{\delta}\right)
$$

We allow the firm to raise its capacity at a stopping time $\tau_{I}$ by a lump size $\xi$ (understood as a $\mathscr{F}_{\tau_{I}}$-measurable random variable) as well as allow it to renege on its debt obligations at a stopping time $\tau_{D}$. The cost incurred to increase the capacity from $\delta$ to $\delta+\xi$ is $k \xi$, with $k>0$. The scale $\Delta^{\nu}$, a stochastic process adapted to the filtration $\mathbb{F}$, depends on the strategy choice $\nu:=\left\{\tau_{I}, \xi, \tau_{D}\right\}$ :

$$
\Delta_{t}^{\nu}(\omega)= \begin{cases}\delta+\xi(\omega), & \tau_{I}(\omega)<t \leq \tau_{D}(\omega) \\ \delta, & \text { otherwise. }\end{cases}
$$

Agents are risk neutral, discount at the constant rate $r$, and have deep pockets. Management acts in the interest of shareholders, which leads to an agency conflict with debtholders. In particular, management chooses a strategy $\hat{\nu}=\left\{\hat{\tau}_{I}, \hat{\xi}, \hat{\tau}_{D}\right\}$ that maximizes shareholder value:

$$
F(x, \delta):=\sup _{\nu} \mathbb{E}_{x, \delta}\left[\int_{0}^{\tau_{D}} e^{-r t} \pi\left(X_{t}, \Delta_{t}^{\nu}\right) \mathrm{d} t-e^{-r \tau_{I}} k \xi \mathbf{1}_{\left(0, \tau_{D}\right)}\left(\tau_{I}\right)\right]
$$

The first right-hand side (RHS) term corresponds to the present value of the FCFEs until default at time $\tau_{D}$, while the second term is the present value of the expansion cost. A key problem is to determine shareholder value (3) and characterize the optimal strategy $\hat{\nu}$ (if one exists). This problem (3) subsumes the unlevered case (for $\beta_{0}=\beta_{1}=0$ ): an unlevered firm is not subject to a distortionary effect of debt and chooses a policy that we call "first best."

It also matters to determine the market value of the debt claim given by

$$
D(x, \delta):=\mathbb{E}_{x, \delta}\left[\int_{0}^{\hat{\tau}_{D}} e^{-r t}\left(\beta_{0}-\beta_{1} X_{t} \sqrt{\Delta_{t}^{\hat{\nu}}}\right) \mathrm{d} t+e^{-r \hat{\tau}_{D}}(1-\alpha) \frac{X_{\hat{\tau}_{D}} \sqrt{\Delta_{\hat{\tau}_{D}}^{\hat{\nu}}}}{r-\mu}\right]
$$

The first RHS term in (4) corresponds to the interest payments until default. In the event of bankruptcy, debtholders receive full ownership of the firm net of proportional bankruptcy costs 
$\alpha \in[0,1] .^{8}$

As in Leland (1994), our model features a choice of capital structure at time 0. Assuming an initial capacity $\delta$ that is already in place and a profitability $x$ (not modeled), initial shareholders choose debt parameters $\left(\hat{\beta}_{0}, \hat{\beta}_{1}\right)$ that maximize total firm value $T V\left(x, \delta ; \beta_{0}, \beta_{1}\right)$, i.e., the sum of shareholder value $F\left(x, \delta ; \beta_{0}, \beta_{1}\right)$ and debt value $D\left(x, \delta ; \beta_{0}, \beta_{1}\right)$.

\section{Model solution}

\subsection{Benchmark default option}

We consider a simple default option as a benchmark. In this case, shareholder value $\varphi$ is

$$
\varphi(x, \delta):=\sup _{\tau_{D}} \mathbb{E}_{x}\left[\int_{0}^{\tau_{D}} e^{-r t} \pi\left(X_{t}, \delta\right) \mathrm{d} t\right]
$$

Before providing an explicit solution to (5) in Theorem 1, we introduce the terms

$$
\begin{array}{rlr}
\eta_{0} & :=-\frac{(1-\theta) \beta_{0}}{r} & {[<0]} \\
\eta_{1} & :=\frac{1+(1-\theta) \beta_{1}}{r-\mu} & {[>0]} \\
\gamma_{A}, \gamma_{B}:=-\frac{\mu-\sigma^{2} / 2}{\sigma^{2}} \pm \sqrt{\left(\frac{\mu-\sigma^{2} / 2}{\sigma^{2}}\right)^{2}+\frac{2 r}{\sigma^{2}}}, & \gamma_{B}<0<1<\gamma_{A} .
\end{array}
$$

Theorem 1 (Benchmark default option). The shareholder value in (5) reads

$$
\varphi(x, \delta)= \begin{cases}0, & x<x_{1}(\delta), \\ \eta_{0}+\eta_{1} x \sqrt{\delta}+\frac{\eta_{0}}{\gamma_{B}-1}\left(\frac{x}{x_{1}(\delta)}\right)^{\gamma_{B}}, & x \geq x_{1}(\delta),\end{cases}
$$

where

$$
x_{1}(\delta) \sqrt{\delta}:=-\frac{\eta_{0}}{\eta_{1}} \frac{\gamma_{B}}{\gamma_{B}-1} \geq 0, \quad \delta>0
$$

\footnotetext{
${ }^{8}$ As in Leland $(1994,1998)$, we assume that, when debtholders become owners of the firm, they decide not to re-leverage the distressed asset; by doing so, the debtholders limit the risk of having to file bankruptcy should the firm not be able to recover quickly.
} 
A. Value function: $\varphi(x, \delta)$

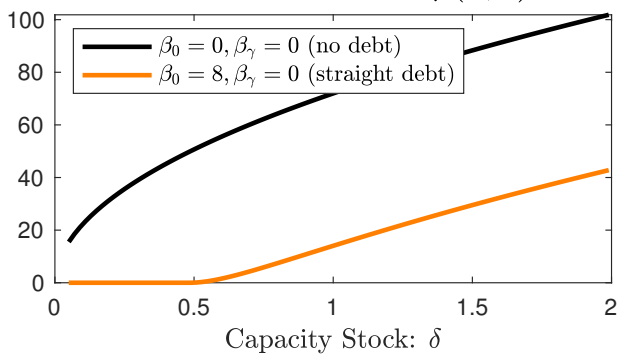

C. Marginal value of $\delta: \varphi_{\delta}(x, \delta)$

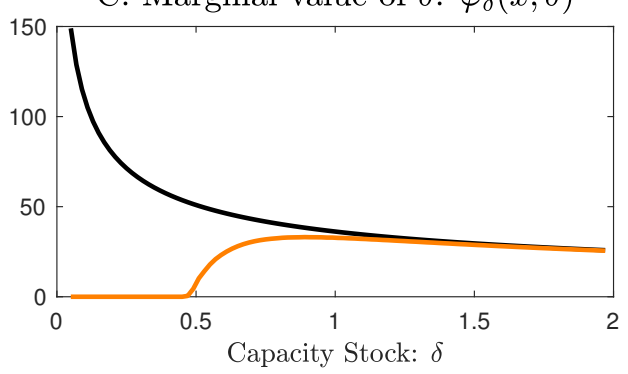

B. Value function: $\varphi(x, \delta)$

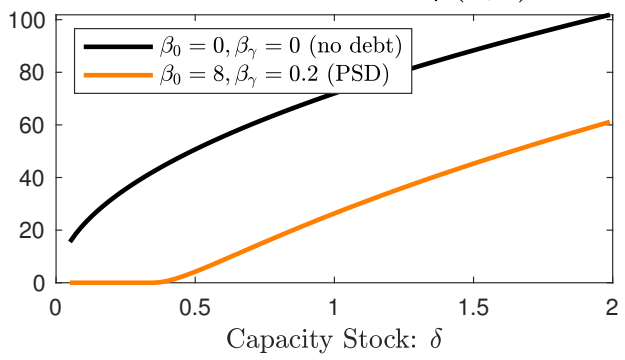

D. Marginal value of $\delta: \varphi_{\delta}(x, \delta)$

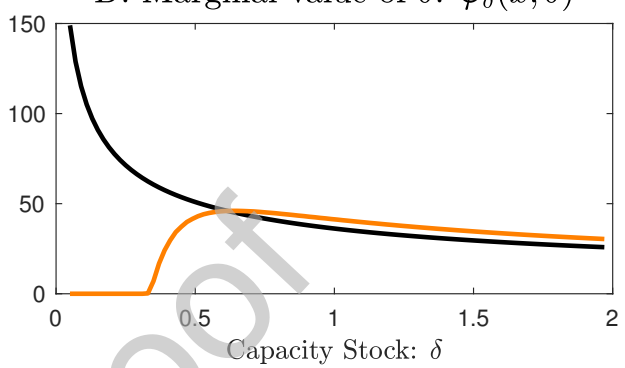

Figure 1. Analysis of marginal benefit of increasing the capital stock. Panel A (resp. Panel B) depicts $\varphi$ with and without straight debt (resp. PSD). Panel C (resp. D) depicts the marginal benefit of increasing the capital stock with and without straight debt (resp. PSD). The parameter values are $r=0.12, \sigma=0.10, \mu=0.01, k=20, \theta=0.1, x=8$.

Following Theorem 1, a firm with a scale $\delta$ optimally defaults if profitability $x$ falls below the level $x_{1}(\delta)$. Otherwise, shareholder value in (9a) comprises the perpetuity value of the FCFEs, $\eta_{0}+\eta_{1} x \sqrt{\delta}$, plus the value of the default option. A larger firm is more able to service its debt and, hence, less likely to default, i.e., $x_{1}^{\prime}(\cdot)<0$.

Panels A and $\mathrm{C}$ of Figure 1 depict respectively the value function $\varphi(x, \cdot)$ and the marginal benefit $\varphi_{\delta}(x, \cdot)$ with and without straight debt (where the under-script denotes the partial derivative). There are two important observations: First, debt financing depresses the marginal benefits. Because debtholders claim the residual value at bankruptcy, shareholders do not fully internalize the benefits from raised scale. This is an illustration of Myers's (1977) debt-overhang problem. Second, under debt financing, returns to scale are increasing for low capacities but decreasing for high capacities. This reflects two opposing effects. Without the default option in (9a), the firm faces diminishing marginal returns because the production function is concave. Yet, raising the scale helps the levered firm reduce default risk, rendering the shareholders' default option less valuable as $\delta$ increases. 
Panel B of Figure 1 compares the value function $\varphi(x, \cdot)$ with PSD (i.e., $\beta_{0}, \beta_{1}>0$ ) versus without debt (i.e., $\left.\beta_{0}=\beta_{1}=0\right)$. Panels $\mathrm{C}$ and $\mathrm{D}$ depict the respective marginal benefit $\delta \mapsto \varphi_{\delta}(\delta, x)$. Importantly, panel D shows that the marginal benefit of increasing scale in the presence of PSD can be larger than the benefit in the absence of debt. Because PSD reduces total debt payments when the firm's operating cashflows are large, this acts as an additional benefit to the shareholders from increasing scale. Through this channel, PSD can mitigate the underinvestment induced by straight debt financing.

\subsection{Optimal scale expansion}

If the firm expanded capacity, it faces the optimal default problem (5) solved in Theorem 1. If it decides to invest, it maximizes the net present value (NPV) from scale expansion given by

$$
\Phi(x, \delta):=\sup _{\xi \geq 0}\{\varphi(x, \delta+\xi)-k \xi\}
$$

Hereafter, we study the mapping $\delta \leftrightarrow \varphi(x, \delta)-k \delta$ in order to characterize the optimal scale expansion. Figure 2 depicts the NPV $\varphi(x, \delta)-k \delta$ obtained by increasing capacity from 0 to $\delta$. First, as shown in Panel A, the firm is better off not to invest in any capacity if profitability $x$ is below the level

$$
x^{\star}:=\frac{1}{\left(1-\gamma_{B}\right) \eta_{1}} \sqrt{2 k \eta_{0} \gamma_{B}\left(2-\gamma_{B}\right)^{\frac{2-\gamma_{B}}{1-\gamma_{B}}}} \geq 0 .
$$

This critical level $x^{\star}$ increases with $\beta_{0}$ but decreases with performance sensitivity $\beta_{1}$. The level $x^{\star}$ vanishes when $\beta_{0}=0$. This implies that debt distorts the investment decision in that the profitability $x$ must be sufficiently high for shareholders to benefit from an expansion.

If profitability is larger, i.e., for $x>x^{\star}$, then the function $\delta \mapsto \varphi(x, \delta)-k \delta$ has a local minimum $\delta_{3}(x)$ obtained by a first-order condition. The local maximum $\delta_{3}(x)$ will be global if and only if profitability $x$ is larger than a level $x^{\star \star}>x^{\star}$. The case for which $\delta_{3}(x)$ is not (resp., is) a global maximum is depicted in Panel B (resp., Panel C) of Figure 2.

If the firm with an initial scale $\delta$ and facing profitability $x$ decides to invest (because it is optimal 

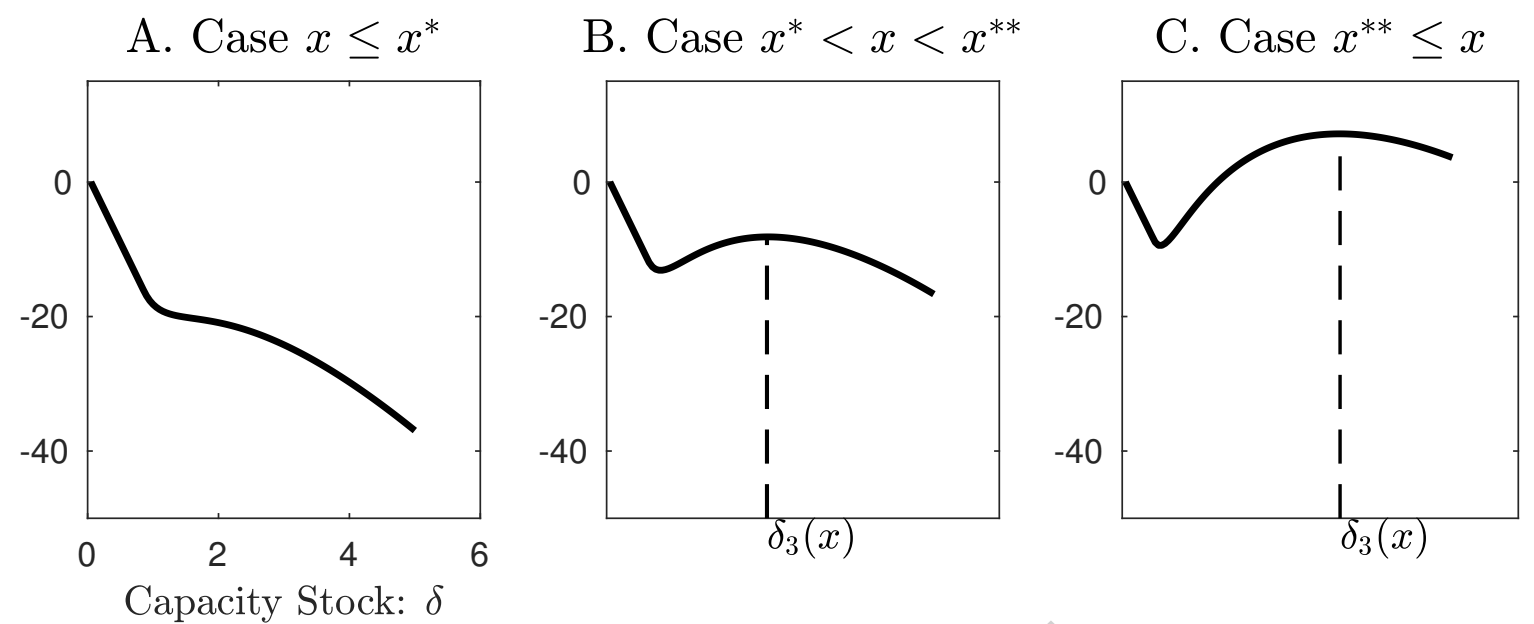

Figure 2. Study of $\delta \mapsto \varphi(x, \delta)-k \delta$. The parameter values are $r=0.12, \sigma=0.10, \mu=0.01$, $\beta_{0}=8, \beta_{1}=0, k=20, \theta=0.1$.

to do so), it raises its scale by a lump $\hat{\xi}(x, \delta)=\delta_{3}(x)-\delta$. It is intuitive that lower profitability $x$ leads to a less ambitious expansion. That is

$$
\delta_{3}^{\prime}(x)=-\frac{\varphi_{\delta x}\left(x, \delta_{3}(x)\right)}{\varphi_{\delta \delta}\left(x, \delta_{3}(x)\right)}>0, \quad x>x^{\star}
$$

as shown in the Appendix. Moreover, as profitability $x$ deteriorates to the level $x^{\star}$, the local maximum $\delta_{3}(x)$ falls to the point

$$
\delta^{\star}:=\frac{\eta_{0} \gamma_{B}}{2 k}\left(2-\gamma_{B}\right)^{\frac{\gamma_{B}}{1-\gamma_{B}}} \geq 0
$$

Henceforth, we restrict attention to the case $\delta \geq \delta^{\star}$, which ensures existence of the inverse $x_{3}(\delta)$ of $\delta_{3}(x)$. We interpret $x_{3}(\delta)$ as the profitability level above which expanding the firm's scale creates shareholder value. A larger firm is less likely to launch an expansion program (i.e., $x_{3}^{\prime}(\cdot)>0$ ). Theorem 2 summarizes our findings about the increase in shareholder value from scale expansion in (10), and is illustrated in panel B of Figure 3. Panel A shows a numerical illustration of the more involved case $\delta<\delta^{*}$. For this case analytical results are beyond the scope of this paper. Intuitively, for small $\delta$, debt overhang is large. Thus, the firm delays investment until higher values of $x$ are reached. However, once firms start investing, they will invest in large (discontinuous) amounts (see 
A. NPV regions with debt

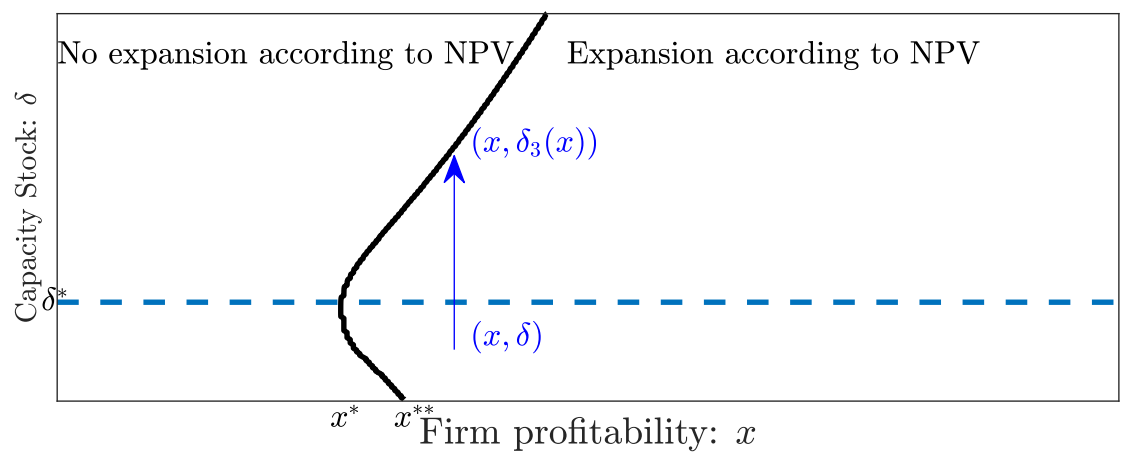

B. NPV regions without debt

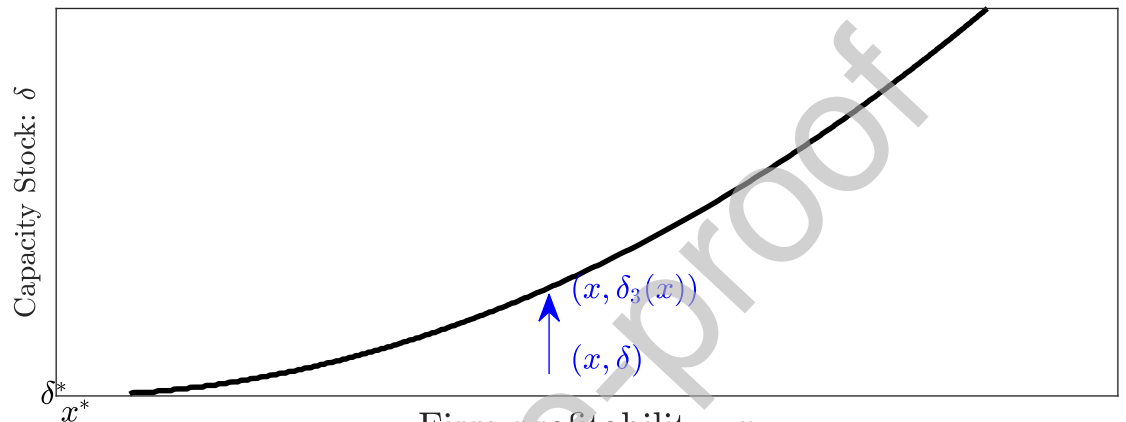

Firm profitability: $x$

Figure 3. Positive vs Negative NPV regions (in the absence of timing considerations). Panel A (resp. B) depicts a case where the firm is levered (resp. unlevered). The parameter values are $r=0.12, \sigma=0.10, \mu=0.01, k=20, \theta=0.1$. PSD values are $\beta_{0}=15, \beta_{1}=1$ for panel $\mathrm{A}$, and $\beta_{0}=0, \beta_{1}=0$ for panel B.

blue arrow in panel A), thereby rendering the obstacle non-differentiable. ${ }^{9}$

Theorem 2 (Shareholder value from scale expansion). We assume that $\delta \geq \delta^{\star}$. The function $\Phi$ in (10) is given by

$$
\Phi(x, \delta)= \begin{cases}\varphi(x, \delta), & x \leq x_{3}(\delta), \\ \varphi\left(x, \delta_{3}(x)\right)-k\left[\delta_{3}(x)-\delta\right], & x>x_{3}(\delta) .\end{cases}
$$

Further, the function $x \mapsto \Phi(x, \delta)$ is continuously differentiable.

We now want to specify the impact of PSD financing on the (static) investment policy:

Corollary 1. The region $\left(x_{3}(\delta), \infty\right)$ in which the management creates shareholder value by expanding is decreasing in the fixed debt installment $\beta_{0}$ and increasing in performance sensitivity $\beta_{1}$.

\footnotetext{
${ }^{9}$ This non-differentiability significantly complicates our analysis and prevents us from deriving analytical results in this case.
} 
A. Comparative statics w.r.t. $\beta_{0}$

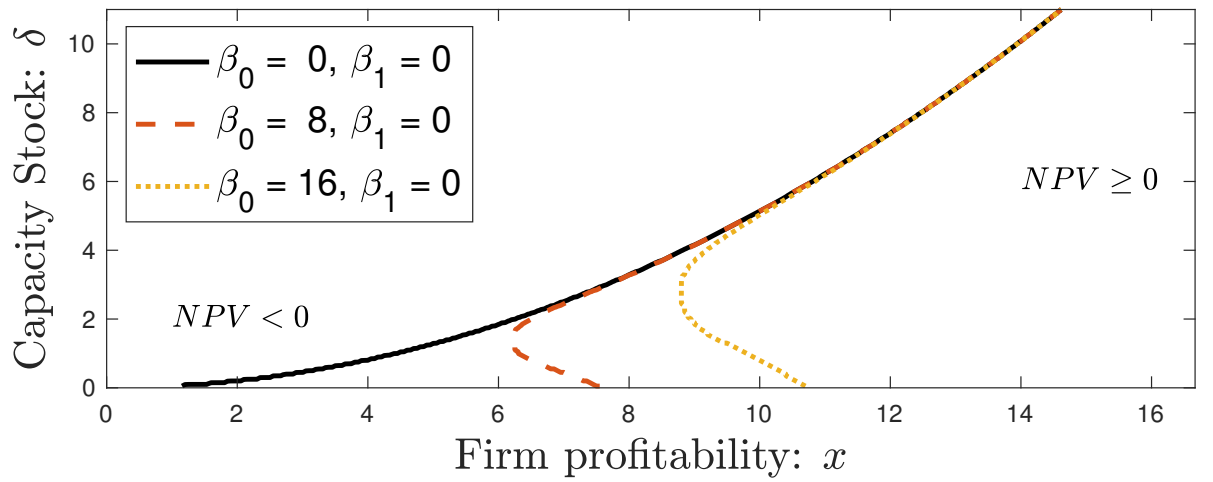

B. Comparative statics w.r.t. $\beta_{1}$

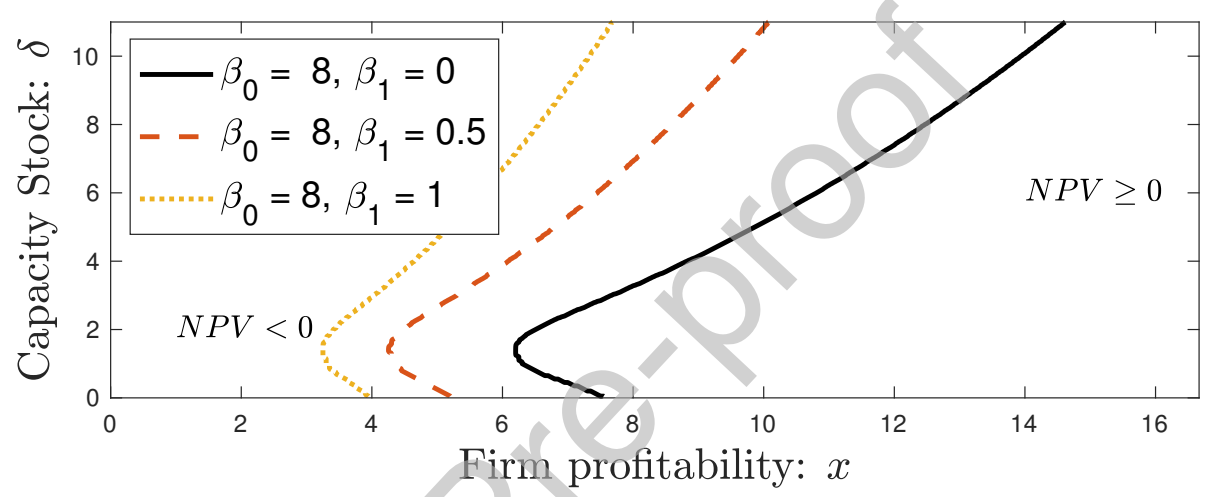

Figure 4. Comparative statics of investment vs noninvestment regions in the absence of timing considerations. Panel A [resp. panel B] depicts comparative statics with respect to the PSD parameter $\beta_{0}$ [resp. $\left.\beta_{1}\right]$. The parameter values are $r=0.12, \sigma=0.10, \mu=0.01, k=20$, $\theta=0.1$.

Figure 4 illustrates the (analytic) findings in Corollary 1. Because the default probability increases in $\beta_{0}$, a larger share of the investment benefits accrues to bondholders if the parties agree on a larger fixed amount $\beta_{0}$. Thus, shareholders are less willing to expand when debt payments are increased as shown in Panel A. The distortion from debt financing is significant when profitability $x$ and initial scale $\delta$ are low, but becomes negligible as profitability $x$ and scale $\delta$ become very large. This is because, in case $x$ and $\delta$ are low, the firm is more likely to default soon after expansion, thereby limiting the extent to which shareholders would benefit from expansion. Panel B of Figure 4 shows that the positive NPV region is increasing in $\beta_{1}$. Larger sensitivity makes expanding capacity more lucrative for shareholders because it leads to reduced debt payments. Yet, because the firm still incurs a fixed payment $\beta_{0}$, it still should not invest for low profitability $x$ and capacity $\delta$.

In summary, Corollary 1 and Figure 4 prove that PSD mitigates underinvestment in the scale 
dimension. We now turn to whether PSD financing will have an impact on the default and expansion timing decisions.

\subsection{Default and expansion timing decisions}

We now discuss the optimal strategy for the shareholder problem $F$ in $(3) .{ }^{10}$ The difference between shareholder value in (3) and the NPV from immediate, optimal scale expansion in (10), namely $\chi:=F-\Phi$, captures the flexibility value or option time value. As a result, shareholders will wait to invest (and default) until the investment (and default) options are "deep in the money."

The solution of this problem can be characterized as a two-threshold strategy (see Appendix D for exact definitions and all mathematical details). That is, the continuation set is of the form $\left(x_{0}(\delta), x_{5}(\delta)\right)$, with $x_{0}(\delta)$ corresponding to the default threshold and $x_{5}(\delta)$ to the investment threshold. Further, the free boundaries $x_{0}(\delta)$ and $x_{5}(\delta)$ satisfy

$$
x_{0}(\delta)<x_{1}(\delta)<x_{3}(\delta)<x_{5}(\delta)
$$

with $x_{1}(\delta)$ defined in $(9 \mathrm{~b})$ and $x_{3}(\delta)$ the inverse of $\delta_{3}(x)$.

Figure 5 depicts the state space $(x, \delta)$ distinguishing the default (to the left of the black curve) and expansion regions (to the right of the red curve) as well as the negative (to the left of the green curve) and positive NPV region (to the right of the green curve). This figure generalizes previous insights to a larger set of scale values: A bigger firm is less likely to default on its debt obligations, but also less likely to expand its scale further.

The impact of PSD financing on the firm's default and expansion timing decisions is particularly interesting. We explore this topic numerically in Figure 6 and conclude that PSD mitigates underinvestment in timing, in addition to the distortionary effect on scale documented in Corollary 1.

According to panel $\mathrm{A}$, agreeing on a larger fixed installment $\beta_{0}$ leads to delayed investment, an effect which arises because shareholders do not fully internalize the investment benefits and because the investment is deferred until the benefits accruing to shareholders are sufficiently large to justify

\footnotetext{
${ }^{10}$ In this section we proceed heuristically, but refer the interested reader to Appendix D for a more rigorous mathematical treatment.
} 
A. Default, Positive NPV, and Investment Regions B. Shareholder value function
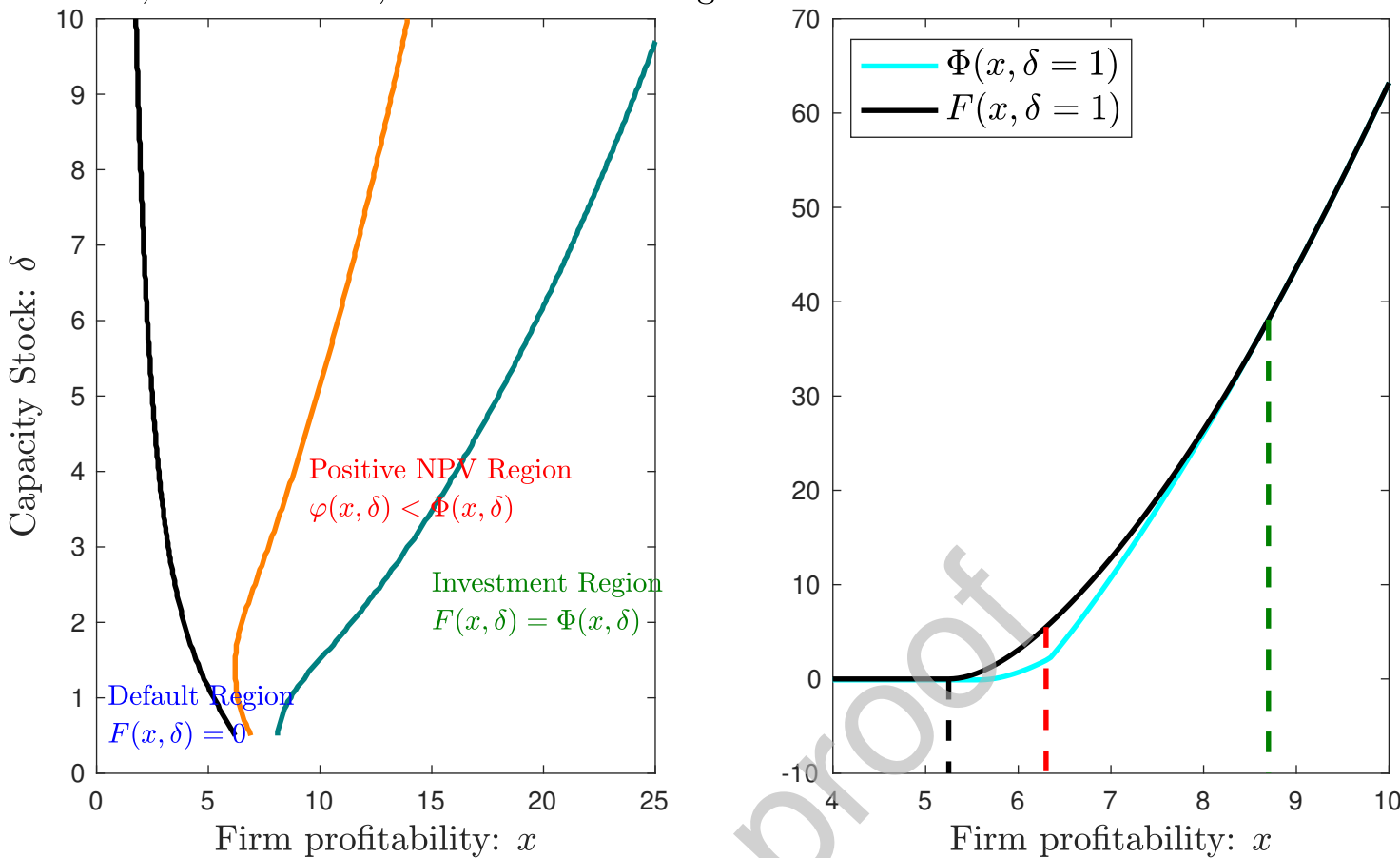

Figure 5. Structure of the multiple regions. This figure depicts the default, positive NPV, and investment regions. The parameter values are $r=0.12, \sigma=0.10, \mu=0.01, \beta_{0}=8, \beta_{1}=0$, $k=20, \theta=0.1$.

the costs, an excessive delay compared to the unlevered benchmark. Moreover, a larger $\beta_{0}$ reduces FCFEs, thereby hastening default. However, panel B shows that a larger sensitivity $\beta_{1}$ to the firm's performance gives an incentive for shareholders to invest earlier. Such is the case because increasing capacity entails a smaller interest payment when $\beta_{1}>0$.

Panel $\mathrm{C}$ shows comparative statics for the investment lump $\hat{\xi}(x, \delta)$ with respect to the fixed debt installment $\beta_{0}$. Higher $\beta_{0}$ renders investment less attractive: investment is not only delayed, but also the scale of investment is distorted downwards. Our paper is the first to simultaneously highlight the time and scale dimensions of the debt-overhang problem: a levered firm invests later and less. ${ }^{11}$ Panel D depicts comparative statics for $\hat{\xi}(x, \delta)$ with respect to performance sensitivity $\beta_{1}$. Higher $\beta_{1}$ makes investment more attractive, thereby leading to a larger investment lump.

As a result, PSD has the potential to mitigate the underinvestment problem in both dimensions: time and scale. Interestingly, PSD can potentially lead to overinvestment, encouraging shareholders

\footnotetext{
${ }^{11}$ Myers (1977) focuses on the effect of debt on the scale of investment, while Mauer and Ott (2000) focuses on the timing of investment.
} 
A. Shareholder value: $F(x)$ with straight debt

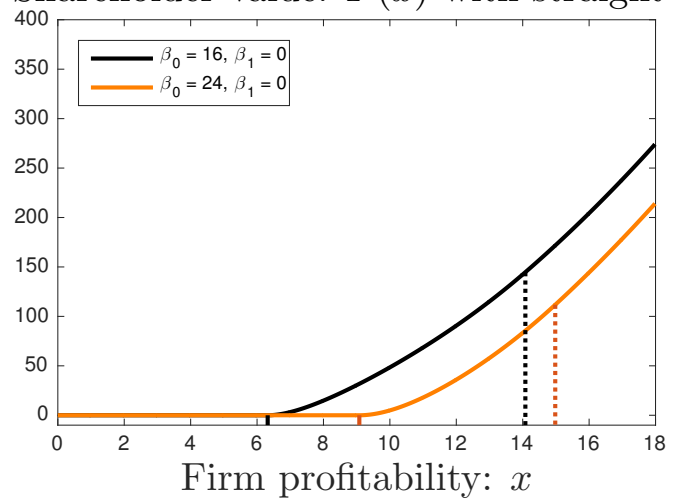

B. Shareholder value: $F(x)$ with PSD

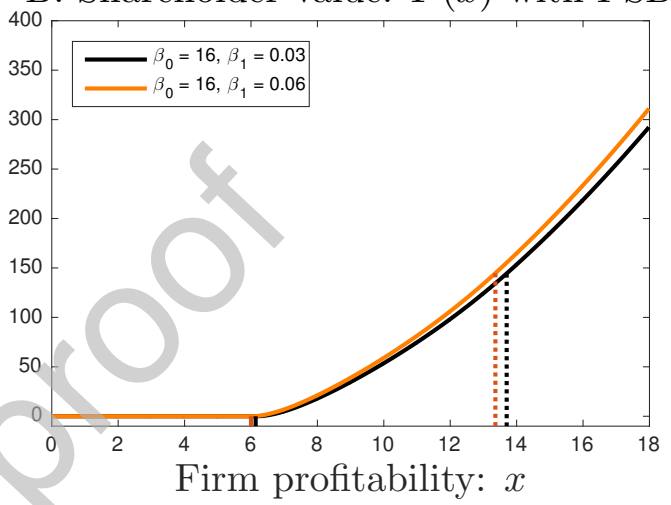

C. Investment lump: $\delta_{3}(x)-\delta$ with straight debt D. Investment lump: $\delta_{3}(x)-\delta$ with PSD
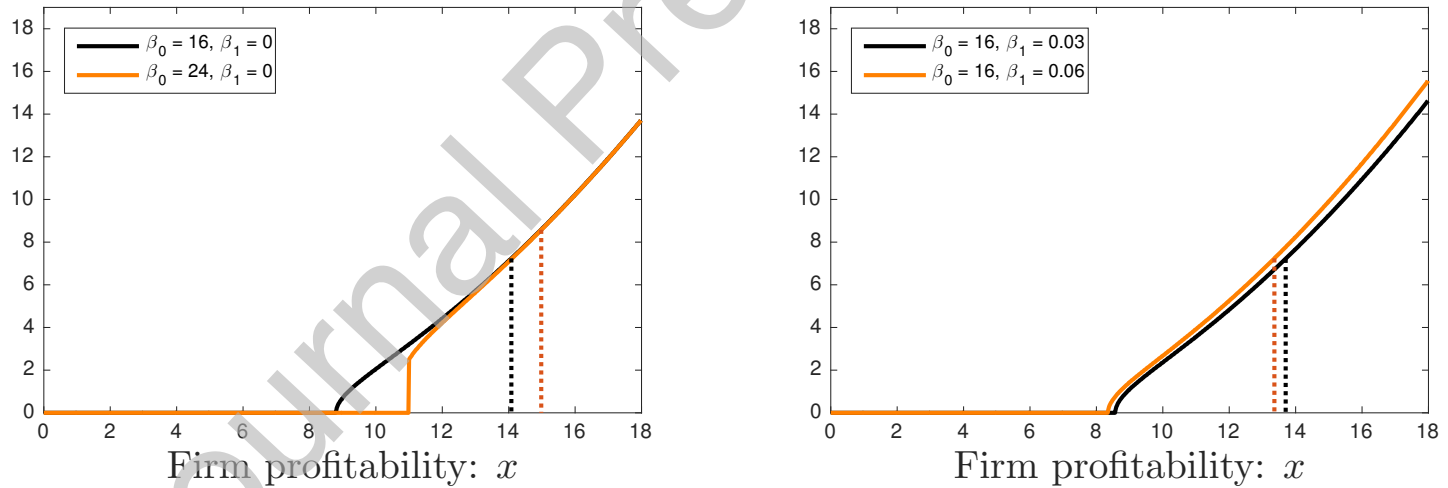

Figure 6. Comparative Statics for shareholder value function $F$ and investment lump $\hat{\xi}$ with respect to $\beta_{0}$ and $\beta_{1}$. The dotted lines corresponds to the investment thresholds $x_{5}(\delta)$. Baseline parameter values are $r=0.12, \sigma=0.10, \mu=0.01, \beta_{0}=16, \beta_{1}=0, k=20, \theta=0.1$, $\delta^{*}=3$, and $\delta=3$. 
to invest in projects sooner than the first-best time and in an amount larger than the first-best capacity. However, economic intuition suggests that overinvestment will not arise for the equilibrium choices of $\beta_{0}$ and $\beta_{1}$. Our numerical results are consistent with this intuition.

We also derive interesting economic insights from the comparative statics depicted in Figure 7. As seen in panel $\mathrm{A}$, higher volatility $\sigma$ delays both the default and investment decisions. The effect on shareholder value $F(x, \delta)$ and investment lump $\hat{\xi}(x, \delta)$ is ambiguous: higher volatility $\sigma$ increases the option value, but it also increases the probability of a costly bankruptcy. Moreover, as shown in panel B, stronger growth $\mu$ benefits shareholders. Shareholders delay default (because a recovery is more likely) and expansion (as the opportunity cost of "killing" the expansion option becomes larger). Finally, panel $\mathrm{C}$ conforms with intuition: a larger investment cost $k$ renders expansion less attractive, so the firm defaults earlier and delays investment further.

A. Shareholder value: $F(x)$

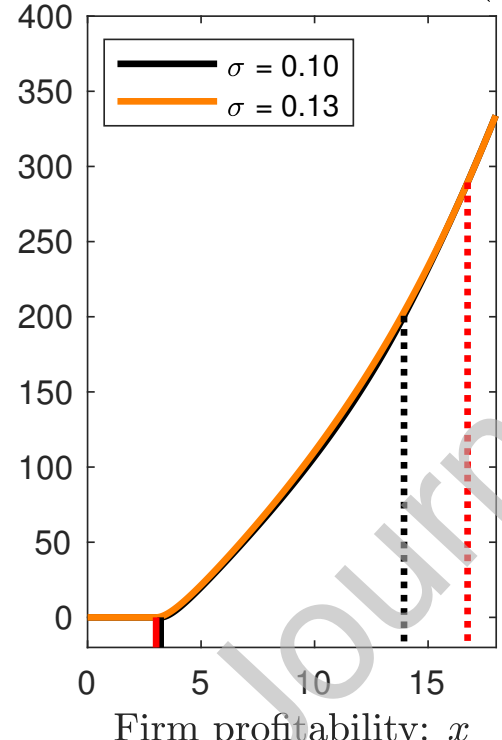

B. Shareholder value: $F(x)$

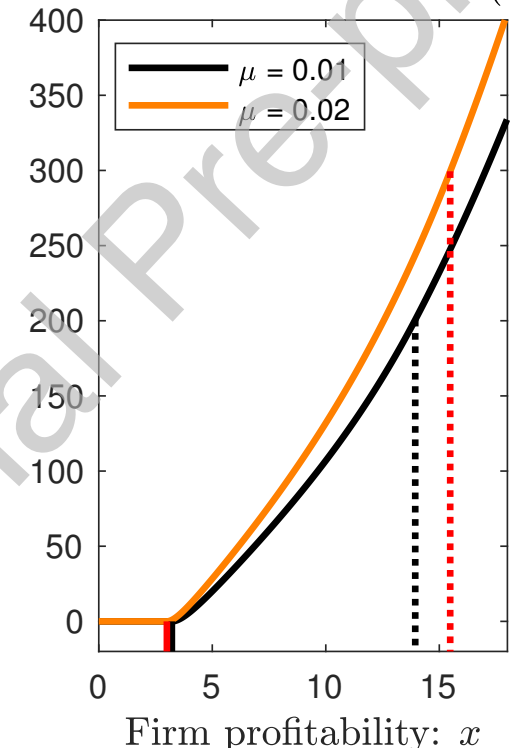

C. Shareholder value: $F(x)$

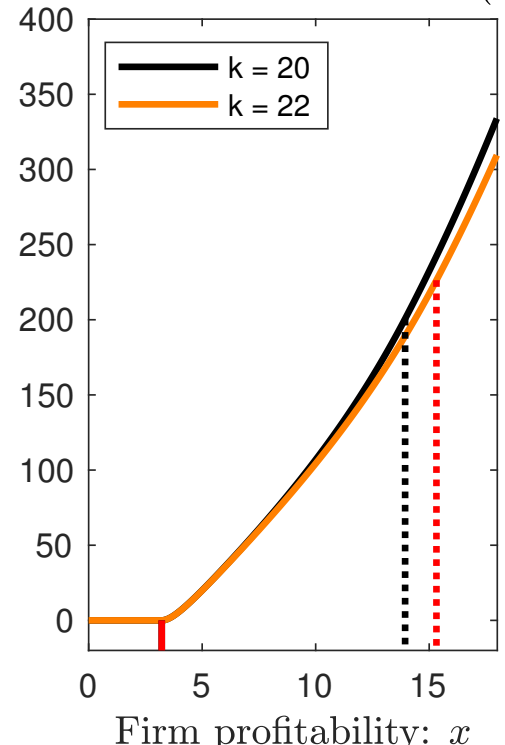

Figure 7. Comparative Statics for shareholder value function $F(x, \delta)$ and investment lump $\hat{\xi}$ with respect to $\sigma, \mu$, and $k$. The solid (resp., dotted) lines corresponds to the default thresholds $x_{0}(\delta)$ (resp., investment thresholds $x_{5}(\delta)$ ). Baseline parameter values are $r=0.12$, $\sigma=0.10, \mu=0.01, \beta_{0}=8, \beta_{1}=0, k=20, \theta=0.1$ and $\delta=3$. 


\section{Optimal PSD financing}

In this section we study optimal PSD financing. First, we show that PSD mitigates debt overhang in both the scaling and timing dimension when holding the market value of debt (4) constant. We show that, for a given loan amount, an increase in the sensitivity of debt to the firm's underlying performance enhances firm value. Then, we allow shareholders to jointly optimize over the amount and sensitivity of debt to maximize total firm value (ex-ante equity value).

\subsection{PSD holding debt value constant}

Following a procedure similar to Diamond and He's (2014), we consider pairs $\left(\beta_{0}, \beta_{1}\right)$ satisfying:

$$
D\left(x, \delta ; \beta_{0}, \beta_{1}\right)=\bar{D}
$$

where debt value is defined in (4) and $\bar{D}>0$ is a constant. The objective is to explore the effect on the firm's default and investment policies of changes to performance sensitivity $\beta_{1}$, while holding the loan amount constant. Figure 8 depicts investment and default policies for three $\left(\beta_{0}, \beta_{1}\right)$ pairs satisfying (16). Panel A shows that higher sensitivity hastens firm's default, by triggering higher payments as the firm's situation deteriorates. However, it also hastens investment and leads to a mitigation in excessive delay due to debt financing. Panel B corroborates our previous intuition that higher sensitivity also leads to a larger investment amount. This figure highlights the fundamental tradeoff regarding the optimal sensitivity of debt: on the one hand higher sensitivity brings investment closer to first-best, but on the other hand it entails higher bankruptcy costs due to earlier liquidation. In the following section these two forces balance out to yield the optimal sensitivity of debt.

\subsection{Capital structure}

Figure 9 depicts total firm value $T V\left(x, \delta ; \beta_{0}, \beta_{1}\right)=F\left(x, \delta ; \beta_{0}, \beta_{1}\right)+D\left(x, \delta ; \beta_{0}, \beta_{1}\right)$ as a function of $\beta_{0}$ and $\beta_{1}$ for given initial profitability $x$ and scale $\delta$. Panel A shows that, in this instance, total 

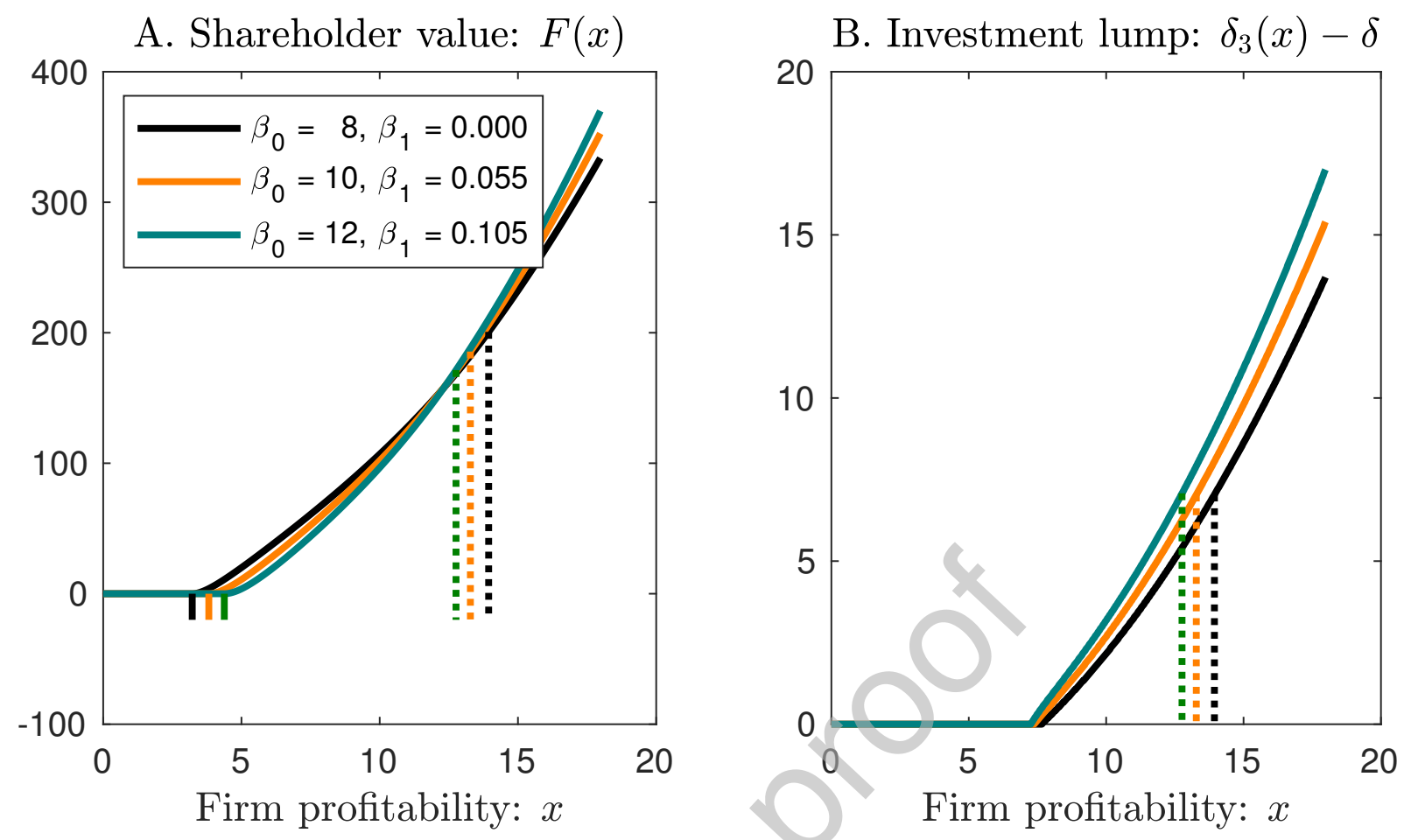

Figure 8. Comparative Statics for shareholder value function $F(x, \delta)$ and investment lump $\hat{\xi}$ with respect to $\beta_{1}$ holding market value of debt $\bar{D}=66.5$ constant. Baseline parameter values are $r=0.12, \sigma=0.10, \mu=0.01, \beta_{0}=8, \beta_{1}=0, k=20, \theta=0.1$ and $\delta=3$.

firm value has a unique interior optimum with $\hat{\beta}_{1}>0$. By identifying a capital structure that maximizes total firm value and includes PSD, this section provides a rationale for the extensive use of this debt instrument.

The optimal capital structure reflects a tradeoff among (a) the tax shield benefits, (b) expected bankruptcy costs, and (c) the distortionary effect of debt on the investment policy. As shown in Panel $\mathrm{B}$, a change in performance sensitivity $\beta_{1}$ (for $\beta_{0}=\hat{\beta}_{0}$ constant) has a nonmonotone effect on total firm value: an increase in $\beta_{1}$ leads to reduced debt payments and lower tax shield benefits, a negative influence on total firm value, but to reduced bankruptcy risk and lower expected bankruptcy costs, a positive influence. We observe a similar tension in Panel $\mathrm{C}$ which depicts total firm value as a function of $\beta_{0}$ (with $\beta_{1}=\hat{\beta}_{1}$ constant): a larger fixed debt payment $\beta_{0}$ enhances tax shield benefits, but increases the bankruptcy risk (and expected related costs) and exacerbates underinvestment. Importantly, the interplay between these three forces has been studied in prior literature highlighting other aspects of the debt contract. Hackbarth and Mauer (2012) explore the 


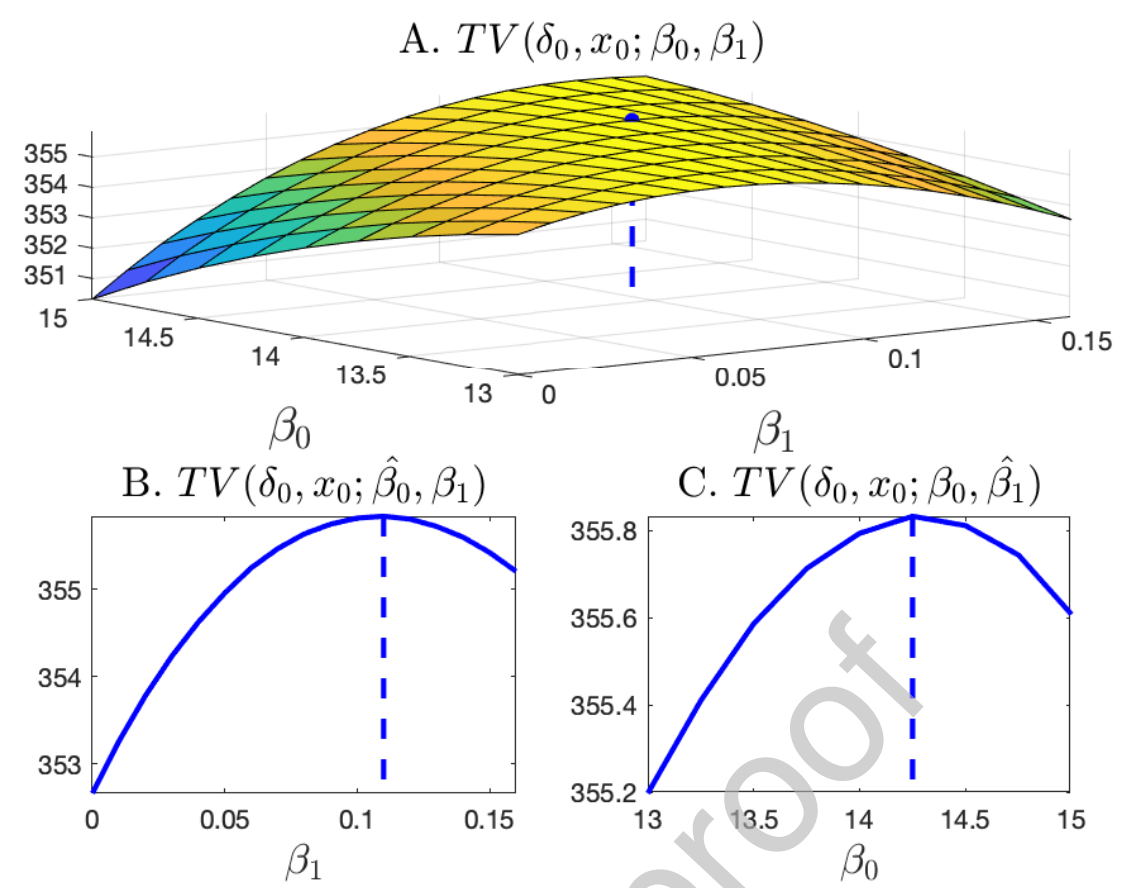

Figure 9. Optimal Capital Structure. Baseline parameter values are $r=0.05, \sigma=0.11$, $\mu=0.015, k=20, \theta=0.1, \delta=2$, and $x=5.5$. Total firm value is maximized for $\hat{\beta}_{0}=14.25$, and $\hat{\beta}_{1}=0.11$ in this example.

seniority of debt and characterize the optimal seniority of debt that maximizes firm value. Similarly, Diamond and He (2014) obtain the optimal maturity of debt that trades off bankruptcy cost (b) and underinvestment (c). They abstract away from the tax advantage of debt (a) in their model. Our contribution complements this literature by exploring the sensitivity of debt that maximizes firm value in a realistic environment with taxes, bankruptcy costs, and a growth opportunity with a choice of timing and scale.

In summary, our model rationalizes the extensive use of performance sensitive clauses in debt contracts (see, e.g., Asquith et al., 2005; Manso et al., 2010), as it delivered an optimal capital structure with $\hat{\beta}_{1}>0$ for firms with available growth options. Importantly, because growth options allow firms to grow faster, our model is consistent with the empirical finding that PSD is more prevalent amongst fast-growth firms (see Table 2 in Manso et al. (2010)). 

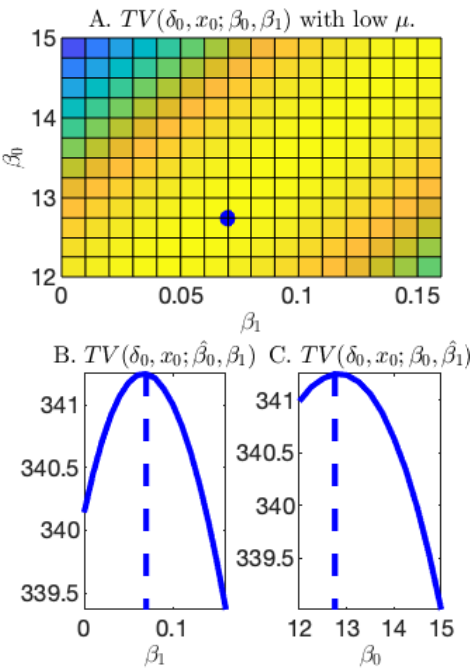

Panel 1 with low $\mu$
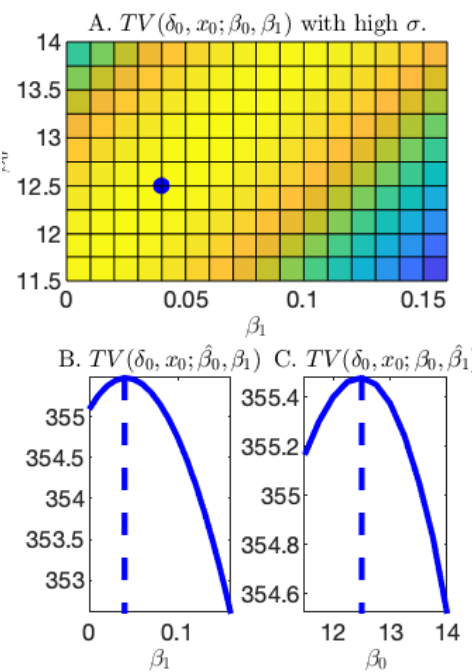

Panel 2 with high $\sigma$
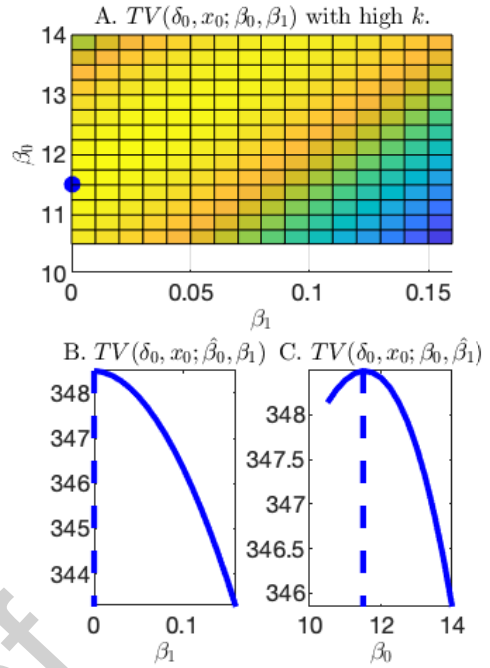

Panel 3 with high $k$

Figure 10. Comparative Statics. Panel 1 depicts optimal capital structure for lower growth firms $(\mu=0.014)$. Panel 2 depicts optimal capital structure for higher volatility firms $(\sigma=0.115)$. Panel 3 depicts optimal capital structure for firms with higher investment costs $(k=21)$. Baseline parameter values are $r=0.05, \sigma=0.11, \mu=0.015, k=20, \theta=0.1, \delta=2$, and $x=5.5$.

\subsection{Comparative Statics and Empirical Implications}

Section 5.3 depicts the optimal capital structure chosen by three different types of firms relative to our baseline case. For each case we show a "heat map" for total firm value as a function of $\left(\beta_{0}, \beta_{1}\right)$, where the blue dot corresponds to the capital structure that maximizes it. Taking comparative statics with respect to the three key parameters characterizing a firm our model, namely the firm's profitability growth rate $\mu$, its volatility $\sigma$, and its investment cost $k$, our model delivers the following empirical implications:

First, firms with higher (lower) profitability growth stand more (less) to gain from available expansion opportunities. Because PSD brings the firm closer to the first best investment policy, our model predicts a wider use of PSD for firms with higher growth rates. Panel 1 depicts the optimal capital structure of a firm with lower profitability growth: $\hat{\beta}_{1}$ goes down from 0.11 to 0.07 , as the baseline growth rate $\mu$ decreases from $1.5 \%$ to $1.4 \%$.

Second, firms with higher (lower) volatility are more (less) likely to default. Because PSD stipulates higher debt payments as the firm's profitability deteriorates, thereby triggering earlier liquidation, 
our model predicts a lower use of PSD for firms with higher volatility. Panel 2 depicts the optimal capital structure of a firm with higher volatility: $\hat{\beta}_{1}$ goes down from 0.11 to 0.04 as the baseline volatility $\sigma$ increases from $11 \%$ to $11.5 \%$.

Finally, firms with higher (lower) investment costs have more (less) to gain from available expansion opportunities. Our model predicts that firms with higher investment costs will make less use of PSD, as the benefit from implementing an optimal investment policy is relatively small. Panel 3 depicts the optimal capital structure of a firm with higher investment costs: $\hat{\beta}_{1}$ goes down from 0.11 to 0 as the baseline cost of increasing capacity $k$ increases from 20 to 21 . That is, in this specific instance, the firm does not use any PSD and only issues straight debt.

\section{Conclusion}

This paper studies the effect of performance-sensitive debt on the shareholders' decisions to default and expand capacity. We show that a levered firm invests later and less than an unlevered firm. However, PSD financing mitigates this underinvestment problem by bringing the firm's investment policy closer to the first-best investment policy. By reducing the misalignments of interests among debt and shareholders, PSD mitigates the agency conflict between shareholders and debtholders and enhances total firm value. This rationale underpins the widespread use of performance-pricing loans.

Our modeling assumptions closely follow the stylized facts described by Asquith et al. (2005) regarding performance sensitive clauses present in bank debt contracts. However, we speculate the key intuition of our results carry over for richer type of debt contracts that feature lower interest payments after good performance such as callable debt and finite maturity debt. Debt instruments with equity features, e.g., convertible bonds, may also help align the interests of various parties.

Our model has certain limitations. We assumed homogeneous beliefs, risk aversion, and time preferences among shareholders and debtholders. In particular, our intuition suggests that PSD can be used as a mechanism to "bridge the gap in beliefs" between optimistic entrepreneurs and creditors; similarly to how short-term debt operates in Landier and Thesmar (2008). A firm generally ex- 
pands capacity in stages, rather than once. The optimal exercise of sequential options will interact with PSD financing. Relaxing this assumption would require refining the techniques developed by Bensoussan and Chevalier-Roignant (2018). Finally, we assumed away liquidity considerations, implicitly assuming that the firm can finance its expansion by reducing dividends and/or issuing new equity acquired by existing shareholders. These directions present opportunities for future research, yet relaxing these assumptions remains a major (technical) challenge. 


\section{References}

Adam, T. R., V. Burg, T. Scheinert, and D. Streitz. 2020. Managerial Biases and Debt Contract Design: The Case of Syndicated Loans. Management Science 66.

Asquith, P., A. Beatty, and J. Weber. 2005. Performance pricing in bank debt contracts. Journal of Accounting and Economics 40:101-128.

Bensoussan, A., and B. Chevalier-Roignant. 2018. Sequential capacity expansion options. Operations research $67: 33-57$.

Bensoussan, A., B. Chevalier-Roignant, and A. Rivera. 2019. An Analytical Approach to Portfolios of Real Options. Tech. rep., SSRN.

Bensoussan, A., and J.-L. Lions. 1982. Applications of Variational Inequalities in Stochastic Control. New York: North-Holland.

Bhanot, K., and A. S. Mello. 2006. Should corporate debt include a rating trigger? Journal of Financial Economics 79:69-98.

Bolton, P., N. Wang, and J. Yang. 2014. Investment, liquidity, and financing under uncertainty. Tech. rep., Columbia University.

Chen, H., and G. Manso. 2017. Macroeconomic risk and debt overhang. Review of Corporate Finance Studies 6:1-38

Dangl, T. 1999. Investment and capacity choice under uncertain demand. European Journal of Operational Research 117:415-428.

Della Seta, M., E. Morellec, and F. Zucchi. 2020. Short-Term Debt and Incentives for Risk-Taking. Journal of Financial Economics 137.

Diamond, D. W., and Z. He. 2014. A theory of debt maturity: the long and short of debt overhang. Journal of Finance 69:719-762.

Dixit, A. K., and R. S. Pindyck. 1994. Investment under Uncertainty. Princeton, NJ: Princeton University Press. 
Edmans, A., and Q. Liu. 2010. Inside debt. Review of finance 15:75-102.

Ericsson, J. 2000. Asset substitution, debt pricing, optimal leverage and maturity. Tech. rep., SSRN \#277529.

Gryglewicz, S., B. Hartman-Glaser, and G. Zheng. Growth options, incentives, and pay for performance: Theory and Evidence. Management Science 66.

Hackbarth, D., and D. C. Mauer. 2012. Optimal priority structure, capital structure, and investment. Review of Financial Studies 25:747-796.

Hackbarth, D., A. Rivera, and T.-Y. Wong. 2018. Optimal short-termism. Tech. rep., CEPR \# DP12588.

He, Z. 2011. A model of dynamic compensation and capital structure. Journal of Financial Economics 100:351-366.

He, Z., and K. Milbradt. 2014. Endogenous liquidity and defaultable bonds. Econometrica 82:14431508 .

He, Z., and W. Xiong. 2012. Dynamic Debt Runs. Review of Financial Studies 25:1799-1843.

Hennessy, C. A. 2004. Tobin's Q, debt overhang, and investment. Journal of Finance 59:1717-1742.

Hugonnier, J., S. Malamud, and E. Morellec. 2014. Capital supply uncertainty, cash holdings, and investment. Review of Financial Studies 28:391-445.

Jensen, M. C., and W. H. Meckling. 1976. Theory of the firm: Managerial behavior, agency costs and ownership structure. Journal of Financial Economics 3:305-360.

Kjenstad, E. C., X. Su, and H. Xia. 2018. Product Market Threats and Performance-Sensitive Debt. Tech. rep., SSRN \#2410568.

Kraus, A., and R. H. Litzenberger. 1973. A state-preference model of optimal financial leverage. Journal of Finance 28:911-922.

Kumar, P., and V. Yerramilli. 2017. Optimal capital structure and investment with real options and endogenous debt costs. Review of Financial Studies 31:3452-3490. 
Lambrecht, B. M., and S. C. Myers. 2008. Debt and managerial rents in a real-options model of the firm. Journal of Financial Economics 89:209-231.

Landier, A., and D. Thesmar. 2008. Financial contracting with optimistic entrepreneurs. Review of Financial Studies 22:117-150.

Leland, H. E. 1994. Corporate debt value, bond covenants, and optimal capital structure. Journal of Finance 49:1213-1252.

Leland, H. E. 1998. Agency costs, risk management, and capital structure. Journal of Finance $53: 1213-1243$.

Manso, G. 2013. Feedback effects of credit ratings. Journal of Financial Economics 109:535-548.

Manso, G., B. Strulovici, and A. Tchistyi. 2010. Performance-sensitive debt. Review of Financial Studies 23:1819-1854.

Mauer, D. C., and S. H. Ott. 2000. Agency costs, underinvestment, and optimal capital structure. In M. Brennan and L. Trigeorgis (eds.), Project flexibility, agency, and competition: New developments in the theory and application of real options., pp. 151-179. Oxford.

Mauer, D. C., and S. Sarkar. 2005. Real options, agency conflicts, and optimal capital structure. Journal of Banking \&3 Finance 29:1405-1428.

McDonald, R., and D. Siegel. 1986. The value of waiting to invest. Quarterly Journal of Economics 101:707-727.

Mello, A. S., and J. E. Parsons. 1992. Measuring the agency cost of debt. Journal of Finance 47:1887-1904.

Miao, J., and N. Wang. 2007. Investment, consumption, and hedging under incomplete markets. Journal of Financial Economics 86:608-642.

Miao, J., and P. Wang. 2011. Bubbles and credit constraints. Tech. rep., SSRN \#1779485.

Morellec, E. 2001. Asset liquidity, capital structure, and secured debt. Journal of Financial Economics 61:173-206. 
Moyen, N. 2007. How big is the debt overhang problem? Journal of Economic Dynamics and Control 31:433-472.

Myers, S. C. 1977. Determinants of corporate borrowing. Journal of Financial Economics 5:147175.

Nishimura, K. G., and H. Ozaki. 2007. Irreversible investment and Knightian uncertainty. Journal of Economic Theory 136:668-694.

Parrino, R., and M. S. Weisbach. 1999. Measuring investment distortions arising from stockholderbondholder conflicts. Journal of Financial Economics 53:3-42.

Philippon, T., and Y. Sannikov. 2007. Real options in a dynamic agency model, with applications to financial development, IPOs, and business risk. Tech. rep., NBER.

Rivera, A. 2020. Dynamic Moral Hazard and Risk-Shifting Incentives in a Leveraged Firm. Journal of Financial and Quantitative Analysis 55:1333-1367.

Sarkar, S., and C. Zhang. 2015. Underinvestment and the design of performance-sensitive debt. International Review of Economics 63 Finance 37:240-253.

Schwartz, E. S. 1982. The pricing of commodity-linked bonds. Journal of Finance 37:525-539.

Shibata, T., and M. Nishihara. 2015. Investment timing, debt structure, and financing constraints. European Journal of Operational Research 241:513-526.

Sundaresan, S., and N. Wang. 2007. Investment under uncertainty with strategic debt service. American Economic Review 97:256-261.

Tchistyi, A., D. Yermack, and H. Yun. 2011. Negative hedging: Performance-sensitive debt and ceos equity incentives. Journal of Financial and Quantitative Analysis 46:657-686.

Titman, S., and S. Tsyplakov. 2007. A dynamic model of optimal capital structure. Review of Finance 11:401-451.

Trigeorgis, L. 1996. Real options. MIT Press.

Trigeorgis, L., and A. E. Tsekrekos. 2018. Real options in operations research: A review. European Journal of Operational Research 270:1-24. 
Whited, T. M. 1992. Debt, liquidity constraints, and corporate investment: Evidence from panel data. Journal of Finance 47:1425-1460.

Wittry, M. 2021. (Debt) Overhang: Evidence from resource extraction. Review of Financial Studies 34:1699-1746. 


\section{Appendices}

\section{A Proof of Theorem 1}

VI. For the problem (5), the DP equation is a variational inequality (VI), which reads

$$
\min \{\varphi(x, \delta) ; \mathcal{L} \varphi(x, \delta)-\pi(x, \delta)\}=0, \quad \text { a.e. } x
$$

with $\mathcal{L}$ given in (41). A boundary condition is $\lim _{x \uparrow \infty} \frac{\varphi(x, \delta)}{\left.\eta_{1} x^{\gamma} \delta^{\epsilon}\right)}=1$. We conjecture the existence of a free boundary $x_{1}(\cdot)$ such that the continuation set is $\mathcal{C}_{1}=\left\{(x, \delta) \in \mathbb{R}_{+}^{2} \mid x>x_{1}(\delta)\right\}$ and we consider the free-boundary problem (FBP)

$$
\begin{array}{rlrl}
\varphi(x, \delta) & =0, & \forall x<x_{1}(\delta), \\
\mathcal{L} \varphi(x, \delta) & =\pi(x, \delta), & \forall x \geq x_{1}(\delta) \\
\varphi\left(x_{1}(\delta), \delta\right) & =0, \\
\partial_{x}^{+} \varphi\left(x_{1}(\delta), \delta\right) & =0 . &
\end{array}
$$

We know that $x \mapsto \eta_{0}+\eta_{1} x \sqrt{\delta}$ is a particular solution of (18b). The function

$$
\mathcal{Q}(\gamma):=r-\gamma \mu-\frac{1}{2} \gamma(\gamma-1) \sigma^{2}
$$

has two distinct roots, $\gamma_{B}<0$ and $\gamma_{A}>1$, given in (8). We are interested in comparative statics of $\gamma_{A / B}$ with respect to the parameters $p \in\{r, \mu, \sigma\}$. We note that $\mathcal{Q}$ is a function of both $p$ and $\gamma$ and that $\gamma_{A / B}$ is a root of $\mathcal{Q}$ which also depends on $p$. We now write

$$
\mathcal{Q}\left(p, \gamma_{A / B}(p)\right)=0
$$

By total differentiation and the chain rule,

$$
\frac{\partial \mathcal{Q}}{\partial p}\left(p, \gamma_{A / B}(p)\right)+\frac{\partial \mathcal{Q}}{\partial \gamma}\left(p, \gamma_{A / B}(p)\right) \times \frac{\mathrm{d} \gamma_{A / B}}{\mathrm{~d} p}(p)=0, \quad p \in\{r, \mu, \sigma\}
$$


so that

$$
\frac{\mathrm{d} \gamma_{A / B}}{\mathrm{~d} p}(p)=-\frac{\frac{\partial \mathcal{Q}}{\partial p}\left(p, \gamma_{A / B}(p)\right)}{\frac{\partial \mathcal{Q}}{\partial \gamma}\left(p, \gamma_{A / B}(p)\right)}, \quad p \in\{r, \mu, \sigma\}
$$

We already know that $\gamma \mapsto \frac{\partial \mathcal{Q}}{\partial \gamma}(p, \gamma)$ is positive at $\gamma_{B}<0$ and negative at $\gamma_{A}>\gamma_{\star}$. Besides, from (19),

$$
\frac{\partial \mathcal{Q}}{\partial p}(p, \gamma)= \begin{cases}>0, & p=r \\ <0, & p \in\{\mu, \sigma\}\end{cases}
$$

It follows that

$$
\begin{array}{ccc}
\frac{\mathrm{d} \gamma_{A}}{\mathrm{~d} r}(r)>0, & \frac{\mathrm{d} \gamma_{A}}{\mathrm{~d} \mu}(\mu)<0, & \frac{\mathrm{d} \gamma_{A}}{\mathrm{~d} \sigma}(\sigma)<0 \\
\frac{\mathrm{d} \gamma_{B}}{\mathrm{~d} r}(r)<0, & \frac{\mathrm{d} \gamma_{B}}{\mathrm{~d} \mu}(\mu)>0, & \frac{\mathrm{d} \gamma_{B}}{\mathrm{~d} \sigma}(\sigma)>0 .
\end{array}
$$

Given the solution to the homogenous ODE, it follows that the ODE (18b) admits a solution of the form

$$
\varphi(x, \delta)=\eta_{0}+\eta_{1} x \sqrt{\delta}+A_{1}(\delta) x^{\gamma_{A}}+B_{1}(\delta) x^{\gamma_{B}}, \quad x \geq x_{1}(\delta)
$$

The three unknowns $A(\cdot), B_{1}(\cdot)$ and $x_{1}(\cdot)$ are obtained from the boundary conditions. We set $A_{1}(\cdot) \equiv 0$. For a given $\delta>0$, it obtains from $(18 \mathrm{c})-(18 \mathrm{~d})$ that $x_{1}(\delta)$ is a root of $x \mapsto \frac{\gamma_{B}-1}{\gamma_{B}} \eta_{1} x \delta^{\frac{1}{2}}+\eta_{0}$ in $\mathbb{R}_{+}$. Because $\gamma \in\left(0, \gamma_{A}\right), \frac{\gamma_{B}-1}{\gamma_{B}} \eta_{1} \sqrt{\delta}>0$ and thus $x \mapsto \frac{\gamma_{B}-1}{\gamma_{B}} \eta_{1} x \delta^{\frac{1}{2}}+\eta_{0}$ increases on $\mathbb{R}_{+}$from $\eta_{0}<0$ to $\infty$, proving the uniqueness of a root in $(9 \mathrm{~b})$. By differentiation, $x_{1}^{\prime}(\delta)<0$, whence $x_{1}(\cdot)$ is monotone decreasing on $\mathbb{R}_{+}$from $\infty$ to 0 and invertible, with its monotone increasing inverse function $\delta_{1}(\cdot)$ given by

$$
\delta_{1}(x):=\left(-\frac{\eta_{0}}{\eta_{1}} \frac{\gamma_{B}}{\gamma_{B}-1} \frac{1}{x}\right)^{2}
$$

It now obtains by differentiation that

$$
\varphi_{x}(x, \delta)=\eta_{1} \delta^{\frac{1}{2}}+\gamma_{B} B_{1}(\delta) x^{\gamma_{B}-1}, \quad x \geq x_{1}(\delta)
$$


so that $B_{1}(\delta)$ obtains $(18 \mathrm{~d})$ as being equal to

$$
B_{1}(\delta)=\frac{\eta_{0}}{\gamma_{B}-1}\left(\frac{\delta^{\frac{1}{2}}}{\lambda}\right)^{\gamma_{B}}
$$

where

$$
\lambda:=-\frac{\eta_{0}}{\eta_{1}} \frac{\gamma_{B}}{\gamma_{B}-1} \quad[>0]
$$

In summary, we just established that the function $\varphi$ in (9a) solves the FBP (18a)-(18d). The proof that the solution $\varphi$ to the FBP (18a)-(18d) solves the VI is fairly standard (and omitted here).

We note that

$$
\begin{aligned}
& \varphi_{\delta}(x, \delta)=\frac{\eta_{1}}{2}\left[x \delta^{-\frac{1}{2}}-\lambda^{1-\gamma_{B}} \delta^{-1+\frac{1}{2} \gamma_{B}} x^{\gamma_{B}}\right] \mathbf{1}_{\left[\delta_{1}(x), \infty\right)}(\delta), \\
& \varphi_{\delta}(x, \delta)=\frac{\eta_{1}}{2} \delta^{-\frac{1}{2}} x^{\gamma}\left[1-\lambda^{1-\gamma_{B}} \delta^{\frac{\gamma_{B}-1}{2}} x^{\gamma_{B}-1}\right] \mathbf{1}_{\left[\delta_{1}(x), \infty\right)}(\delta)
\end{aligned}
$$

\section{B Proof of Theorem 2}

Local maximum at $\delta_{3}(x)$. Because we can write (10) as

$$
\Phi(x, \delta)=\sup _{\Delta \geq \delta}\{\varphi(x, \Delta)-k \Delta\}+k \delta,
$$

it is meaningful to study $\delta \mapsto \varphi(x, \delta)-k \delta$. We have

$$
\begin{aligned}
\varphi_{\delta \delta}(x, \delta) & =\frac{1}{2} \eta_{1}\left(-\frac{1}{2} \delta^{-\frac{3}{2}} x+\left(1-\gamma_{B} \frac{1}{2}\right) \lambda^{1-\gamma_{B}} \delta^{-\frac{3}{2} \gamma_{B}} x^{\gamma_{B}}\right) \mathbf{1}_{\left[\delta_{1}(x), \infty\right)}(\delta) \\
& =-\frac{1}{4} \eta_{1} \delta^{-\frac{3}{2}} x\left(1-\left(2-\gamma_{B}\right) \lambda^{1-\gamma_{B}} \delta^{-\frac{1}{2}\left(1-\gamma_{B}\right)} x^{\gamma_{B}-1}\right) \mathbf{1}_{\left[\delta_{1}(x), \infty\right)}(\delta) .
\end{aligned}
$$

We obtain

$$
\varphi_{\delta \delta}(x, \delta)=-\frac{1}{4} \eta_{1} \delta^{-\frac{3}{2}} x\left[1-\left(\frac{\left[2-\gamma_{B}\right]^{\frac{2}{1-\gamma_{B}}} \delta_{1}(x)}{\delta}\right)^{\frac{1-\gamma_{B}}{2}}\right] \mathbf{1}_{\left[\delta_{1}(x), \infty\right)}(\delta)
$$


So the function $\delta \mapsto \varphi_{\delta}(x, \delta)$ vanishes on $\left(0, \delta_{1}(x)\right)$, increases on $\left[\delta_{1}(x),\left[2-\gamma_{B}\right]^{\frac{2}{1-\gamma_{B}}} \delta_{1}(x)\right]$ and decreases on $\left[\left[2-\gamma_{B}\right]^{\frac{2}{1-\gamma_{B}}} \delta_{1}(x), \infty\right)$. The global maximum attained at $\left[2-\gamma_{B}\right]^{\frac{2}{1-\gamma_{B}}} \delta_{1}(x)$ is

$$
\varphi_{\delta}\left(x,\left[2-\gamma_{B}\right]^{\frac{2}{1-\gamma_{B}}} \delta_{1}(x)\right)=\frac{1}{4} \eta_{1}\left(\lambda\left[2-\gamma_{B}\right]^{\frac{1}{1-\gamma_{B}}}\right)^{-1} x^{2} \frac{1-\gamma_{B}}{1-\frac{1}{2} \gamma_{B}}
$$

We define the point $x^{\star}$ in (11). We distinguish several cases:

A. If $\underline{x \leq x^{\star}}, \partial_{\delta} \varphi\left(x,\left[2-\gamma_{B}\right]^{\frac{2}{1-\gamma_{B}}} \delta_{1}(x)\right) \leq k$ and so $\delta \mapsto \varphi(x, \delta)-k \delta$ is decreasing in $[0, \infty)$. From (28),

$$
\Phi(x, \delta)=\varphi(x, \delta), \quad \text { if } x \leq x^{\star}
$$

B. If $\underline{x>x^{\star}}, \varphi_{\delta}(x, \delta)=k$ has two solutions in $\left[\delta_{1}(x), \infty\right)$, which we note $\delta_{3}(x)$ and $\tilde{\delta}_{3}(x)$ with

$$
\delta_{3}(x)>\left[2-\gamma_{B}\right]^{\frac{2}{1-\gamma_{B}}} \delta_{1}(x)>\tilde{\delta}_{3}(x), \quad x>x^{\star} .
$$

The function $\delta \mapsto \partial_{\delta} \varphi(x, \delta)$ increases at $\tilde{\delta}_{3}(x)$ and decreases at $\delta_{3}(x)$ and so the function $\delta \mapsto \varphi(x, \delta)-k \delta$ attains a minimum at $\tilde{\delta}_{3}(x)$ and a unique local maximum at $\delta_{3}(x)$. By definition of $\delta_{3}(x)$ and total differentiation,

$$
\delta_{3}^{\prime}(x)=-\frac{\varphi_{\delta x}\left(x, \delta_{3}(x)\right)}{\varphi_{\delta \delta}\left(x, \delta_{3}(x)\right)}
$$

It obtains from $(29)$ and $(31)$ that $\varphi_{\delta \delta}\left(x, \delta_{3}(x)\right)<0$. Furthermore,

$$
\varphi_{x \delta}(x, \delta)=\frac{1}{2} \eta_{1} \delta^{-\frac{1}{2}}\left[1-\gamma_{B}\left(\lambda \delta^{-\frac{1}{2}}\right)^{1-\gamma_{B}} x^{-1+\gamma_{B}}\right]
$$

which is positive. So, $\delta_{3}^{\prime}(x)$ in (32) is strictly positive and $\delta_{3}(\cdot)$ monotone increasing on $\left(x^{\star}, \infty\right)$. We note that $\tilde{\delta}_{3}\left(x^{\star}\right)=\delta_{2}\left(x^{\star}\right)=\delta_{3}\left(x^{\star}\right)$ and denote this value $\delta^{\star}$. To show that $\delta_{3}(x) \rightarrow \infty$ as $x \rightarrow \infty$, we note that

$$
\frac{1}{2} \eta_{1}\left[\delta_{3}(x)^{-\frac{1}{2}} x-\lambda^{1-\gamma_{B}} \delta_{3}(x)^{-1+\frac{1}{2} \gamma_{B}}\right]=k
$$


It follows from $\delta_{3}(x)>\delta^{\star}$ that $\delta_{3}(x)^{-1+\frac{1}{2} \gamma_{B}} x \downarrow 0$ as $x \uparrow \infty$. Therefore,

$$
\delta_{3}(x)^{\frac{1}{2}} \geq \frac{\eta_{1}}{2 k} x-C
$$

where $C$ is a constant.

We can now conclude that:

Lemma. (i) For any $x<x^{*}$ the function $\delta \mapsto \varphi(x, \delta)-k \delta$ admits a unique local and global maximum in $[0, \infty)$, at $\delta=0$.

(ii) For any $x \geq x^{*}$ the function $\delta \mapsto \varphi(x, \delta)-k \delta$ admits a unique local maximum $\delta_{3}(x)$ in $\left[\delta_{1}(x), \infty\right)$. Moreover, the function $\delta_{3}(\cdot)$ is monotone increasing on its domain $\left[x^{\star}, \infty\right)$ from $\delta^{\star}$ given in (13) to $\infty$.

Global maximum. We introduce the function

$$
\phi(x):=\varphi\left(x, \delta_{3}(x)\right)-k \delta_{3}(x)
$$

which is defined on the domain $\left(x^{\star}, \infty\right)$. The local maximum $\delta_{3}(x)$ in case (ii) of the Lemma above will not be a global maximum unless the value attained at that local maximum, $\phi(x)$, is above the other local maximum 0 attained at $\delta=0$. We thus study the sign of $\phi(\cdot)$ on the domain $\left(x^{\star}, \infty\right)$. It follows from total differentiation and definition of $\delta_{3}(x)$ that $\phi^{\prime}(x)=\varphi_{x}\left(x, \delta_{3}(x)\right)$. It is immediate from (9a) that $\phi^{\prime}(x) \geq 0$ and, hence, that $\phi(\cdot)$ is monotone increasing.

From (9a) and (34), we can re-write the function (35) as

$$
\phi(x)=\eta_{0}+\frac{1}{2} \eta_{1} \delta_{3}(x)^{\frac{1}{2}} x+\frac{\eta_{0}\left(1-\frac{1}{2} \gamma_{B}\right)}{\gamma_{B}-1}\left(\frac{\delta_{3}(x)^{\frac{1}{2}} x}{\lambda}\right)^{\gamma_{B}}
$$

We define

$$
\delta_{3}\left(x^{\star}\right)=\delta^{\star}:=\left(\frac{\lambda\left[2-\gamma_{B}\right]^{\frac{1}{1-\gamma_{B}}}}{x^{\star}}\right)^{2} .
$$


It follows that

$$
\phi\left(x^{\star}\right)=\eta_{0}+\frac{1}{2} \eta_{1} \lambda\left[2-\gamma_{B}\right]^{\frac{1}{1-\gamma_{B}}}+\frac{\eta_{0}}{2} \frac{\left[2-\gamma_{B}\right]^{\frac{1}{1-\gamma_{B}}}}{\gamma_{B}-1},
$$

which we can simplify to

$$
\phi\left(x^{\star}\right)=\eta_{0}\left[1-\frac{1}{2}\left(2-\gamma_{B}\right)^{\frac{1}{1-\gamma_{B}}}\right]
$$

thanks to (11) and (25). Because $\eta_{0}<0$, we have

$$
\operatorname{sgn}\left\{\phi\left(x^{\star}\right)\right\}=\operatorname{sgn}\left\{2-\gamma_{B}-2^{1-\gamma_{B}}\right\}
$$

The second-order derivative of $x \mapsto 2-x-2^{1-x}$ is $-\ln (2)^{2} 2^{1-x}<0$, so the first-order derivative $x \mapsto-1+\ln (2) 2^{1-x}$ is monotone decreasing on $(-\infty, 0)$ from $+\infty$ to a positive number. It follows that the function $x \mapsto 2-x-2^{1-x}$ is monotone increasing on $(-\infty, 0)$ from $-\infty$ to 0 . Because $\gamma_{B}<0$, it can assert that $\phi\left(x^{\star}\right)<0$.

We now remark that the function $\phi(x) \rightarrow \infty$ as $x \rightarrow \infty$ because $\delta_{3}(x) \rightarrow \infty$. So we can now conclude that:

Lemma. The function $\phi(\cdot)$ defined in (35) is monotone increasing on $\left[x^{\star}, \infty\right)$. There is a unique point $x^{\star \star}>x^{\star}$ such that $\phi(x) \lesseqgtr 0$ iff $x \lesseqgtr x^{\star \star}$.

From the above Lemma, we conclude that $\delta_{3}(x)$ will be a global maximum iff $x \geq x^{\star \star}$.

NPV upon expansion. We now want to determine $\Phi$ in (10):

1) We recall the expression for $\Phi$ in (30) if $\underline{x \leq x^{\star}}$ : .

2) If $\underline{x \geq x^{\star \star}}$, then $\phi(x) \geq 0$. The function $\Phi$ defined in (10) is thus

$$
\Phi(x, \delta)= \begin{cases}\phi(x)+k \delta, & \delta<\delta_{3}(x), \\ \varphi(x, \delta), & \delta \geq \delta_{3}(x)\end{cases}
$$

The function $\delta_{3}(\cdot)$ is monotone increasing on $\left(x^{\star}, \infty\right)$ from $\delta^{\star}$ to $\infty$, so its inverse $x_{3}(\cdot)$ is monotone increasing on $\left(\delta^{\star}, \infty\right)$. We now assume $\underline{\delta} \geq \delta^{\star}$. Then $x_{3}(\delta) \geq x_{3}\left(\delta^{\star}\right)=x^{\star}$. We can 
now re-write (36) as

$$
\Phi(x, \delta)= \begin{cases}\phi(x)+k \delta, & x_{3}(\delta)<x, \\ \varphi(x, \delta), & x_{3}(\delta) \geq x,\end{cases}
$$

We can now assert the expression for $\Phi$ in (14) in the case $\delta \geq \delta^{\star}$. If $\underline{\delta \geq \delta^{\star}}$, we see from (37) that $\Phi(\cdot, \delta)$ is continuous; it is also continuously differentiable by the definitions of $\phi(\cdot)$ in $(35)$ and of $\delta_{3}(\cdot)$. This completes the proof of Theorem 2 .

\section{Proof of Corollary 1}

Suppose that $(x, \delta)$ is in the positive NPV region, i.e., that

$$
\Phi\left(x, \delta ; \beta_{0}\right)>\varphi\left(x, \delta ; \beta_{0}\right)
$$

which implies that $\exists \xi>0$ such that

$$
\varphi\left(x, \delta+\xi ; \beta_{0}\right)-k \xi>\varphi\left(x, \delta ; \beta_{0}\right) .
$$

We claim that

$$
\frac{d}{d \beta_{0}}\left(\varphi\left(x, \delta+\xi ; \beta_{0}\right)-\varphi\left(x, \delta ; \beta_{0}\right)\right)<0
$$

which would imply that

$$
\varphi\left(x, \delta+\xi ; \beta_{0}^{\prime}\right)-k \xi>\varphi\left(x, \delta ; \beta_{0}^{\prime}\right)
$$

for $\beta_{0}^{\prime}<\beta_{0}$. Therefore

$$
\Phi\left(x, \delta ; \beta_{0}^{\prime}\right)>\varphi\left(x, \delta ; \beta_{0}^{\prime}\right)
$$

which means that $(x, \delta) \in I\left(\beta_{0}^{\prime}, \beta_{1}\right)$.

We now prove claim (38). In order to prove the claim we precompute the following quantities:

$$
\frac{\mathrm{d} \eta_{0}}{\mathrm{~d} \beta_{0}}=-\frac{1-\theta}{r}<0, \quad \frac{\mathrm{d} \eta_{0}}{\mathrm{~d} \beta_{1}}=0
$$




$$
\begin{gathered}
\frac{\mathrm{d} \eta_{1}}{\mathrm{~d} \beta_{0}}=0, \quad \frac{\mathrm{d} \eta_{1}}{\mathrm{~d} \beta_{1}}=\frac{1-\theta}{Q(\gamma)}>0 \\
\frac{\mathrm{d} \lambda}{\mathrm{d} \beta_{0}}=-\frac{1}{\eta_{1}} \frac{\gamma_{\beta}}{\gamma_{\beta}-\gamma} \frac{d \eta_{0}}{\mathrm{~d} \beta_{0}}>0, \quad \frac{\mathrm{d} \lambda}{\mathrm{d} \beta_{1}}=\frac{\eta_{0}}{\eta_{1}^{2}} \frac{\gamma_{\beta}}{\gamma_{\beta}-\gamma} \frac{\mathrm{d} \eta_{1}}{\mathrm{~d} \beta_{1}}<0
\end{gathered}
$$

Replacing from Theorem 1 we obtain that:

$$
\begin{gathered}
\varphi\left(x, \delta+\xi ; \beta_{0}\right)-\varphi\left(x, \delta ; \beta_{0}\right)=\eta_{0}+\eta_{1} x^{\gamma}(\delta+\xi)^{\frac{1}{2}}+\frac{\eta_{0} \gamma}{\gamma_{B}-\gamma}\left(\frac{x}{x_{1}(\delta+\xi)}\right)^{\gamma_{B}}-k \xi-\eta_{0}-\eta_{1} x^{\gamma} \delta^{\frac{1}{2}}-\frac{\eta_{0} \gamma}{\gamma_{B}-\gamma}\left(\frac{x}{x_{1}(\delta)}\right)^{\gamma_{B}} \\
=\eta_{1} x^{\gamma}\left[(\delta+\xi)^{\frac{1}{2}}-\delta^{\frac{1}{2}}\right]+\frac{\eta_{0} \gamma}{\gamma_{B}-\gamma}\left[\left(\frac{x}{x_{1}(\delta+\xi)}\right)^{\gamma_{B}}-\left(\frac{x}{x_{1}(\delta)}\right)^{\gamma_{B}}\right]-k \xi
\end{gathered}
$$

where $x_{1}(\delta)=\left(\frac{\lambda}{\delta^{\frac{1}{2}}}\right)^{\frac{1}{\gamma}}$. Deriving with respect to $\beta_{0}$ yields:

$$
\begin{gathered}
\underbrace{\frac{d \eta_{0}}{d \beta_{0}}}_{-} \underbrace{\frac{\gamma x^{\gamma_{3}}}{\gamma_{B}-\gamma}}_{-} \underbrace{\left[\left(x_{1}(\delta+\xi)\right)^{-\gamma_{B}}-\left(x_{1}(\delta)\right)^{-\gamma_{B}}\right]}_{-}+ \\
+\underbrace{\frac{\eta_{0} \gamma x^{\gamma_{\beta}}}{\gamma_{B}-\gamma}}_{+} \underbrace{\left(\frac{-\gamma_{B}}{\gamma}\right)}_{+} \underbrace{\left[x_{1}(\delta+\xi)^{-\gamma_{B}}-x_{1}(\delta)^{-\gamma_{B}}\right]}_{-} \underbrace{\frac{1}{\lambda} \frac{d \lambda}{d \beta_{0}}<0}_{+}
\end{gathered}
$$

Similarly, suppose that $(x, \delta)$ is in the positive NPV region, i.e., that

$$
\Phi\left(x, \delta ; \beta_{1}\right)>\varphi\left(x, \delta ; \beta_{1}\right)
$$

which implies that $\exists \xi>0$ such that

$$
\varphi\left(x, \delta+\xi ; \beta_{1}\right)-k \xi>\varphi\left(x, \delta ; \beta_{1}\right)
$$

We claim that

$$
\frac{d}{d \beta_{1}}\left(\varphi\left(x, \delta+\xi ; \beta_{1}\right)-\varphi\left(x, \delta ; \beta_{1}\right)\right)>0,
$$

which would imply that

$$
\varphi\left(x, \delta+\xi ; \beta_{1}^{\prime}\right)-k \xi>\varphi\left(x, \delta ; \beta_{1}^{\prime}\right),
$$


for $\beta_{1}^{\prime}>\beta_{1}$. Therefore

$$
\Phi\left(x, \delta ; \beta_{1}^{\prime}\right)>\varphi\left(x, \delta ; \beta_{1}^{\prime}\right)
$$

which means that $(x, \delta) \in I\left(\beta_{0}, \beta_{\gamma}^{\prime}\right)$.

Deriving with respect to $\beta_{0}$ yields:

$$
\begin{gathered}
\underbrace{\frac{d \eta_{1}}{d \beta_{1}} x}_{+} \underbrace{\left[(\delta+\xi)^{\frac{1}{2}}-\delta^{\frac{1}{2}}\right]}_{+}+ \\
+\underbrace{\frac{\eta_{0} \gamma x^{\gamma_{\beta}}}{\gamma_{B}-\gamma}}_{+} \underbrace{\left(\frac{-\gamma_{B}}{\gamma}\right)}_{+} \underbrace{\left[x_{1}(\delta+\xi)^{-\gamma_{B}}-x_{1}(\delta)^{-\gamma_{B}}\right]}_{-} \underbrace{\frac{1}{\lambda} \frac{d \lambda}{d \beta_{1}}}_{-}>0
\end{gathered}
$$

\section{Appendix for Section 4.3}

We now discuss the approach to solve for shareholder value $F$ in (3). The difference between shareholder value in (3) and the NPV from immediate, optimal scale expansion in (10), namely $\chi:=F-\Phi$, captures the flexibility value (resp., "option time value") to use the terminology of real (resp., financial) options. If we make the assumption $\delta \geq \delta^{\star}$, then the function $\Phi(\cdot, \delta)$ is continuously differentiable (see Theorem 2). We introduce the second-order differential operator $\mathcal{L}$ given by

$$
\mathcal{L} f(x):=r f(x)-\mu x f^{\prime}(x)-\frac{1}{2} \sigma^{2} x^{2} f^{\prime \prime}(x)
$$

We interpret $-\mathcal{L} \Phi$ as the excess capital gain from delaying and $\Pi:=\pi-\mathcal{L} \Phi$ as the temporary economic profit or loss accruing to shareholders when the management delays decision making. Using standard techniques (see the appendix), we can re-write the stochastic control problem (3) as an optimal stopping problem, namely

$$
\chi(x, \delta)=\sup _{\tau} \quad \mathbb{E}_{x} \int_{0}^{\tau} e^{-r t} \Pi\left(X_{t}, \delta\right) \mathrm{d} t \quad \text { for } \delta \geq \delta^{\star}
$$

We assume that the option value $\chi(x, \delta)$ vanishes as $x \downarrow 0$. We will also need to ensure that the payoff in (42) is finite. If we manage to solve (42), we can easily recover the value function $F$ in 
(3) by using $F=\chi+\Phi$, with $\Phi$ given in (14).

We use dynamic programming to solve (42). The dynamic programming equation corresponding to this optimal stopping problem is

$$
0=\min \{\chi ; \mathcal{L} \chi-\Pi\} \quad \text { for } \delta \geq \delta^{\star} \text { and a.e. } x>0 .
$$

The equation (43) has an appealing economic interpretation. A first inequality, $\chi \geq 0$, asserts that flexibility is of value to shareholders. A second inequality, $\mathcal{L} \chi \geq \Pi$, states that the total return from holding the real option (weakly) exceeds the FCFE and the capital gain from delaying the exercise. Finally, the condition $\chi \times[\mathcal{L} \chi-\Pi]=0$ asserts that the decisions to stay put or act (i.e., default or expand) are mutually exclusive. Below, we express sufficient conditions under which the following theorem holds:

Theorem 3 (Flexibility value $\chi$ for $\delta>\delta^{\star}$ ). The continuation set $\mathcal{C}$ for the optimal stopping problem $(42)$ is of the form $\left(x_{0}(\delta), x_{5}(\delta)\right)$ where $x_{0}(\delta)$ and $x_{5}(\delta)$ are free boundaries satisfying

$$
x_{0}(\delta)<x_{1}(\delta)<x_{3}(\delta)<x_{5}(\delta) .
$$

The flexibility value $\chi(\cdot, \delta)$ in $(42)$ is continuously differentiable and given by

$$
\chi(x, \delta)= \begin{cases}0, & 0 \leq x<x_{0}(\delta) \\ \frac{2}{\left(\gamma_{A}-\gamma_{B}\right) \sigma^{2}}\left[x^{\gamma_{B}} \int_{x_{0}(\delta)}^{x} \frac{\Pi(z, \delta)}{z^{\gamma_{B}+1}} \mathrm{~d} z+x^{\gamma_{A}} \int_{x}^{x_{5}(\delta)} \frac{\Pi(z, \delta)}{z^{\gamma_{A}+1}} \mathrm{~d} z\right], & x_{0}(\delta) \leq x \leq x_{5}(\delta), \\ 0, & x>x_{5}(\delta) .\end{cases}
$$

Before proving this theorem we provide some intuition for the growth condition, namely $\gamma_{A}>$ 2. Formally, for very large profitability $x$, the default option term in (9a) becomes negligible. Consequently, for large profitability $x$, the amount $\delta_{3}(x)$-obtained by the first-order condition $\varphi_{\delta}\left(x, \delta_{3}(x)\right)=k$-increases in a quadratic manner. That is, the FCFE $x \sqrt{\delta_{3}(x)}$ grows quadratically. The condition $\gamma_{A}>2$ ensures that the FCFE stream has a finite perpetuity value. The condition $\gamma_{A}>2$ is less likely to hold when the parameters $\mu$ and $\sigma$ take on larger values; this is because an increase in any of them leads to a greater economic profit from delaying. By contrast, 
the condition is more likely to hold when the discount rate $r$ increases because a delayed cash flow yields a lower present value.

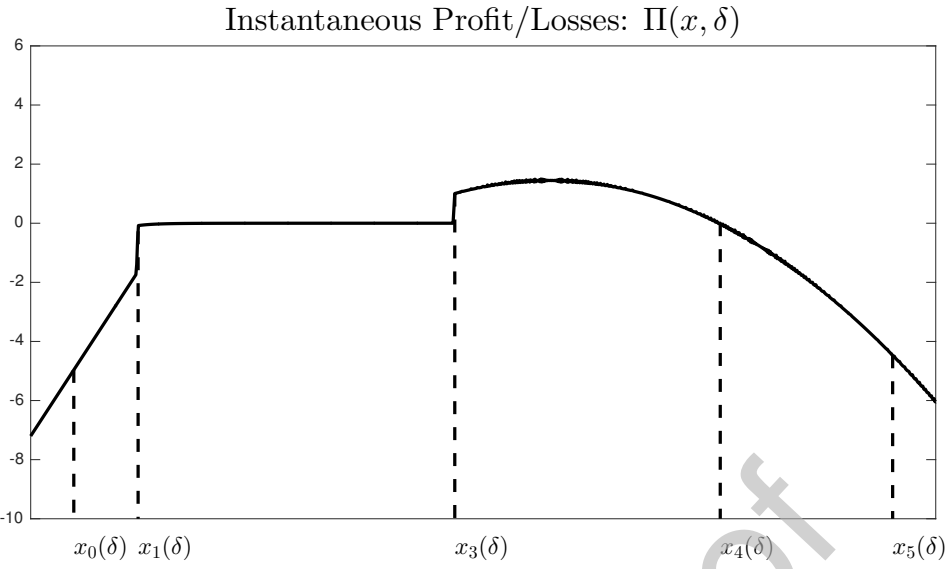

Figure 11. Variations of the function $x \mapsto \Pi(x, \delta)$ for $\delta \geq \delta^{\star}$ and $\gamma_{A}>2$. The parameter values are $r=0.12, \sigma=0.10, \mu=0.01, k=20, \theta=0.1$. Debt parameters are $\beta_{0}=8$ and $\beta_{1}=0$.

Figure 11 plots the function $\Pi(\cdot, \delta)$-assuming $\delta \geq \delta^{\star}$ and $\gamma_{A}>2$-and helps us intuit the threshold ranking in (44). We recall the threshold $x_{1}(\delta)$ in $(9 \mathrm{~b})$ under which a firm that cannot expand defaults and the NPV threshold $x_{3}(\delta)$. The firm incurs temporary economic losses when it decides not to default for low profitability $x<x_{1}(\delta)$ or when it decides not to expand for large profitability $x>x_{4}(\delta)$. When $x_{1}(\delta)<x<x_{3}(\delta)$ the firm earns no adjusted profits, but prefers to delay in the expectation of making future profits. As per Figure 11, the firm makes an economic profit from delaying if $x_{3}(\delta)<x<x_{4}(\delta)$. Losses may be conjunctural: the shareholders may accumulate economic losses in the short or medium term, yet may expect a recovery [if $0<x<x_{1}(\delta)$ ] or a downturn [if $\left.x>x_{4}(\delta)\right]$. The shareholders will therefore delay until the economic losses are sufficient-namely, when $0<x<x_{0}(x)$ or $x>x_{5}(\delta)$ - to justify making an irreversible decision. This logic is consistent with classical real options reasoning (see, e.g., McDonald and Siegel, 1986), but here applied to a more complex setup involving decisions on the expansion $\left(\tau_{I}\right)$ and default times $\left(\tau_{D}\right)$ as well as on the optimal scale expansion $(\xi)$. 


\section{D.1 Proof of Theorem 3}

Problem reformulation. Because $\xi$ is a random variable that is $\mathscr{F}_{\tau_{I}}$-measurable, we can re-write the stochastic control problem (3) thanks to (10) as

$$
F(x, \delta)=\sup _{\tau_{I}, \tau_{D}} \mathbb{E}_{x, \delta}\left[\int_{0}^{\tau_{I} \wedge \tau_{D}} e^{-r t} \pi\left(X_{t}, \delta\right) \mathrm{d} t+e^{-r \tau_{I}} \Phi\left(X_{\tau_{I}}, \delta\right) \mathbf{1}_{\left(0, \tau_{D}\right)}\left(\tau_{I}\right)\right]
$$

Further, if we introduce $\tau:=\tau_{I} \wedge \tau_{D}$, we can express (3) as an optimal stopping problem:

$$
F(x, \delta)=\sup _{\tau} \mathbb{E}_{x, \delta}\left[\int_{0}^{\tau} e^{-r t} \pi\left(X_{t}, \delta\right) \mathrm{d} t+e^{-r \tau} \Phi\left(X_{\tau}, \delta\right)\right] .
$$

We recall the operator $\mathcal{L}$ in (41). If $\delta \geq \delta^{\star}$, then $\Phi(\cdot, \delta)$ is $C^{1}$, so we can apply Dynkin's formula (see Bensoussan and Lions, 1982, Thm. 8.5, pp. 185-86) obtaining

$$
\mathbb{E}_{x, \delta}\left[e^{-r \tau} \Phi\left(X_{\tau}, \delta\right)\right]=\Phi(x, \delta)-\mathbb{E}_{x, \delta} \int_{0}^{\tau} e^{-r t} \mathcal{L} \Phi\left(X_{t}, \delta\right) \mathrm{d} t
$$

for an arbitrary $\mathbb{F}$-stopping time $\tau$. The expression (42) readily obtains once we introduce the functions $\chi:=F-\Phi$ and $\Pi:=\pi-\mathcal{L} \Phi$. For convenience of notations, we drop the dependence of the thresholds and functions on the parameter $\delta$ when there is no confusion.

Study of the function II. From Theorems 1 and 2,

$$
\Pi(x)=r \eta_{0}+\eta_{1}(r-\mu) x \sqrt{\delta}, \quad x<x_{1} .
$$

We further note that $\mathcal{Q}\left(\gamma_{B}\right)=0$ to obtain

$$
\Pi(x)=0, \quad x_{1}<x<x_{3} .
$$


The case $x>x_{3}$ requires tedious calculations. By total differentiation of $\phi(\cdot)$ in $(35)$, we obtain

$$
\begin{aligned}
\phi^{\prime}(x) & =\varphi_{x}\left(x, \delta_{3}(x)\right)+\varphi_{\delta}\left(x, \delta_{3}(x)\right) \delta_{3}^{\prime}(x), \\
\phi^{\prime \prime}(x) & =\varphi_{x x}\left(x, \delta_{3}(x)\right)+2 \varphi_{x \delta}\left(x, \delta_{3}(x)\right) \delta_{3}^{\prime}(x)+\varphi_{\delta \delta}\left(x, \delta_{3}(x)\right) \delta_{3}^{\prime}(x)^{2}+\varphi_{\delta}\left(x, \delta_{3}(x)\right) \delta_{3}^{\prime \prime}(x) .
\end{aligned}
$$

It follows that

$$
\begin{aligned}
\mathcal{L} \phi(x)= & {\left[r \varphi\left(x, \delta_{3}(x)\right)-\mu x \varphi_{x}\left(x, \delta_{3}(x)\right)-\frac{1}{2} \sigma^{2} x^{2} \varphi_{x x}\left(x, \delta_{3}(x)\right)\right]-k\left[r \delta_{3}(x)-\mu x \delta_{3}^{\prime}(x)-\frac{1}{2} \sigma^{2} x^{2} \delta_{3}^{\prime \prime}(x)\right] } \\
& -\mu x \varphi_{\delta}\left(x, \delta_{3}(x)\right) \delta_{3}^{\prime}(x)-\frac{1}{2} \sigma^{2} x^{2}\left[2 \varphi_{x \delta}\left(x, \delta_{3}(x)\right) \delta_{3}^{\prime}(x)+\varphi_{\delta \delta}\left(x, \delta_{3}(x)\right) \delta_{3}^{\prime}(x)^{2}+\varphi_{\delta}\left(x, \delta_{3}(x)\right) \delta_{3}^{\prime \prime}(x)\right] .
\end{aligned}
$$

We recall that $\left[x_{3}, \infty\right)$ is a subset of $\left[x_{1}, \infty\right)$, the continuation region for (5) given in Theorem 1 .

Hence,

$$
r \varphi\left(x, \delta_{3}(x)\right)-\mu x \varphi_{x}\left(x, \delta_{3}(x)\right)-\frac{1}{2} \sigma^{2} x^{2} \varphi_{x}\left(x, \delta_{3}(x)\right)=r \eta_{0}+(r-\mu) \eta_{1} x \sqrt{\delta_{3}(x)} .
$$

Consequently,

$$
\begin{aligned}
\mathcal{L} \phi(x)= & r \eta_{0}+\mathcal{Q}(\gamma) \eta_{1} x \sqrt{\delta_{3}(x)}-r k \delta_{3}(x) \\
& -\mu x \delta_{3}^{\prime}(x)\left[\varphi_{\delta}\left(x, \delta_{3}(x)\right)-k\right]-\frac{1}{2} \sigma^{2} x^{2} \delta_{3}^{\prime \prime}(x)\left[\varphi_{\delta}\left(x, \delta_{3}(x)\right)-k\right] \\
& -\frac{1}{2} \sigma^{2} x^{2} \delta_{3}^{\prime}(x)\left[2 \varphi_{x \delta}\left(x, \delta_{3}(x)\right)+\varphi_{\delta \delta}\left(x, \delta_{3}(x)\right) \delta_{3}^{\prime}(x)\right] .
\end{aligned}
$$

It now obtains from the definition of $\delta_{3}(x)$ and (32) that

$$
\mathcal{L} \phi(x)=r \eta_{0}+(r-\mu) \eta_{1} x \sqrt{\delta_{3}(x)}-r k \delta_{3}(x)+\frac{1}{2} \sigma^{2} x^{2} \frac{\varphi_{x \delta}\left(x, \delta_{3}(x)\right)^{2}}{\varphi_{\delta \delta}\left(x, \delta_{3}(x)\right)} .
$$

Substituting (47) into the expression for $\Pi$ yields

$$
\Pi(x)=-(r-\mu) \eta_{1} x\left(\sqrt{\delta_{3}(x)}-\sqrt{\delta}\right)+r k\left(\delta_{3}(x)-\delta\right)-\frac{1}{2} \sigma^{2} x^{2} \frac{\varphi_{x \delta}\left(x, \delta_{3}(x)\right)^{2}}{\varphi_{\delta \delta}\left(x, \delta_{3}(x)\right)}, \quad x>x_{3}
$$


To summarize, the function $g$ can be written as

$$
\Pi(x)= \begin{cases}r \eta_{0}+\eta_{1}(r-\mu) x \sqrt{\delta}, & x<x_{1}, \\ 0, & x_{1}(\delta)<x<x_{3}, \\ -(r-\mu) \eta_{1} x\left(\sqrt{\delta_{3}(x)}-\sqrt{\delta}\right)+r k\left(\delta_{3}(x)-\delta\right)-\frac{1}{2} \sigma^{2} x^{2} \frac{\varphi_{x \delta}\left(x, \delta_{3}(x)\right)^{2}}{\varphi_{\delta \delta}\left(x, \delta_{3}(x)\right)}, & x>x_{3} .\end{cases}
$$

Discontinuities arise because $\Phi(\cdot, \delta)$ is not $C^{2}$ at $x_{1}$ and $x_{3}$.

We now discuss the sign of $\Pi(\cdot)$. The function $\Pi(\cdot)$ is monotone increasing on $\left(0, x_{1}\right)$. It now obtains from (9b), (19) and (25) that

$$
\Pi(x)<\frac{\eta_{0}}{\gamma_{B}-1}\left(\gamma_{B} \mu-r\right)<0, \quad \text { if } x<x_{1} .
$$

Further, it is immediate from (48) that

$$
\Pi\left(x_{3}+\right)=-\frac{1}{2} \sigma^{2} x^{2} \frac{\varphi_{x \delta}\left(x_{3}, \delta\right)^{2}}{\varphi_{\delta \delta}\left(x_{3}, \delta\right)}>0 .
$$

We want to study the behavior of $\Pi(\cdot)$ as $x \rightarrow \infty$. From the definition of $\delta_{3}(x)$, we have

$$
k \delta_{3}(x)=\frac{\eta_{1}}{2} \sqrt{\delta_{3}(x)} x\left[1-\left(\frac{\delta_{1}(x)}{\delta_{3}(x)}\right)^{\frac{1-\gamma_{B}}{2}}\right]
$$

We have from (29) and (33) that

$$
\frac{\varphi_{x \delta}\left(x, \delta_{3}(x)\right)^{2}}{\varphi_{\delta \delta}\left(x, \delta_{3}(x)\right)}=-\frac{\eta_{1} \sqrt{\delta_{3}(x)}}{x} \frac{\left(1-\gamma_{B}\left[\lambda x^{-1} \delta_{3}(x)^{-\frac{1}{2}}\right]^{1-\gamma_{B}}\right)^{2}}{1-\left[\left[2-\gamma_{B}\right]^{\frac{1}{1-\gamma_{B}}} \lambda x^{-1} \delta_{3}(x)^{-\frac{1}{2}}\right]^{1-\gamma_{B}}}
$$

From (22)

$$
\frac{\varphi_{x \delta}\left(x, \delta_{3}(x)\right)^{2}}{\varphi_{\delta \delta}\left(x, \delta_{3}(x)\right)}=-\frac{\eta_{1} \sqrt{\delta_{3}(x)}}{x} \frac{\left(1-\gamma_{B}\left(\frac{\delta_{1}(x)}{\delta_{3}(x)}\right)^{\frac{1-\gamma_{B}}{2}}\right)^{2}}{1-\left[2-\gamma_{B}\right]\left(\frac{\delta_{1}(x)}{\delta_{3}(x)}\right)^{\frac{1-\gamma_{B}}{2}}}
$$


We recall that $\delta_{1}(\cdot)$ vanishes as $x \rightarrow \infty$ while $\delta_{3}(\cdot)$ goes to $\infty$. From (49) and (50) we conclude

$$
\frac{\Pi(x)}{\eta_{1} x \sqrt{\delta_{3}(x)}} \rightarrow-\frac{r-\sigma^{2}}{2}-\mu, \quad \text { as } \quad x \rightarrow \infty
$$

Furthermore, we can infer from (49) that

$$
\frac{\sqrt{\delta_{3}(x)}}{x} \rightarrow \frac{\eta_{1}}{2 k} \quad \text { as } \quad x \rightarrow \infty
$$

Combining the limits (51) and (52), we conclude

$$
\frac{\Pi(x)}{x^{2}} \rightarrow-\frac{\mathcal{Q}(2)}{4 k} \eta_{1}^{2} \quad \text { as } x \rightarrow \infty
$$

We know that

$$
\mathcal{Q}(2) \lesseqgtr 0 \Longleftrightarrow 2 \gtreqless \gamma_{A} \text {. }
$$

From (53) we can now assert that $\frac{\Pi(x)}{x^{2}}$ goes to a negative (resp., positive) constant if $\gamma_{A}>2$ (resp., $0<\gamma_{A}<2$ ). To simplicity, we exclude the case $\gamma_{A}=2$. We conclude that:

Lemma. The function $\Pi(x)$ is discontinuous at $x_{1}$ and $x_{3}$. It is negative on $\left(0, x_{1}\right)$ and vanishes on $\left(x_{1}, x_{3}\right)$. It is positive at the right of $x_{3}$ and goes to $-\infty$ if $\gamma_{A}>0$ and to $+\infty$ if $\gamma_{A}<2$.

If $\delta \geq \delta^{\star}$ and $\gamma_{A}>2$, we define $x_{4}>x_{3}$ as the point such that $\Pi\left(x_{4}\right)=0$ and $\Pi(x)<0$ for all $x>x_{4}$. We thus established the pattern in Figure 11 except for the sign in $x_{3}<x<x_{4}$ which we could not prove.

Restriction $\gamma_{A}>2$. Given optionality, the value function $\chi(\cdot)$ in $(42)$ must weakly exceed

$$
\underline{\chi}(x)=\mathbb{E}_{x} \int_{0}^{\infty} e^{-r t} g\left(X_{t}\right) \mathrm{d} t
$$

The functional representation of (54) is the solution to the second-order ODE

$$
\mathcal{L} \underline{\chi}(x)=\Pi(x), \quad \text { for } \delta \geq \delta^{\star}
$$


while the functional representation of (42) is the solution $\chi$ to the VI (43).

Given the behavior of $\Pi(\cdot)$ in (53), the function $\chi(\cdot)$ in (54) is finite iff

$$
\mathbb{E}_{x} \int_{0}^{\infty} e^{-r t} X_{t}^{2} \mathrm{~d} t<\infty
$$

But we know that

$$
\mathbb{E}_{x} \int_{0}^{\infty} e^{-r t} X_{t}^{2} \mathrm{~d} t=x^{2} \int_{0}^{\infty} e^{-\mathcal{Q}(2) t} \mathrm{~d} t
$$

It follows that the condition (56) is satisfied iff $\mathcal{Q}(2)>0$, i.e., iff $\gamma_{A}>2$. If $0<\gamma_{A}<2$, the solution to the VI (43) does not have the probabilistic interpretation (42).

Free-boundary problem. To solve the VI (43), we first conjecture a structure for the continuation set, namely of the form $\left(x_{0}, x_{5}\right)$ with free boundaries $x_{0}$ and $x_{5}$ such that

$$
0<x_{0}<x_{1}<x_{4}<x_{5}
$$

The corresponding FBP is

$$
\begin{array}{rlrl}
\mathcal{L} \chi(x) & =\Pi(x), \quad x \in\left(x_{0}, x_{5}\right), & \\
\chi\left(x_{0}\right)=\chi\left(x_{5}\right) & =0, & & \\
\chi^{\prime}\left(x_{0}\right)=\chi^{\prime}\left(x_{5}\right) & =0 . & &
\end{array}
$$

As usual, we guess a solution to the ODE (58a) of the form

$$
\chi(x)=A(x) x^{\gamma_{A}}+B(x) x^{\gamma_{B}} \quad \text { with } \quad A^{\prime}(x) x^{\gamma_{A}}+B^{\prime}(x) x^{\gamma_{B}} \equiv 0 \quad \text { for } x \in\left(x_{0}, x_{5}\right) .
$$

It follows from (58a) that

$$
A^{\prime}(x)=-\frac{2}{\left(\gamma_{A}-\gamma_{B}\right) \sigma^{2}} \frac{\Pi(x)}{x^{\gamma_{A}+1}} \quad \text { and } \quad B^{\prime}(x)=\frac{2}{\left(\gamma_{A}-\gamma_{B}\right) \sigma^{2}} \frac{\Pi(x)}{x^{\gamma_{B}+1}}
$$


The smooth-fit conditions (58b) and (58c) imply that

$$
A\left(x_{0}\right)=B\left(x_{0}\right)=A\left(x_{5}\right)=B\left(x_{5}\right)=0 .
$$

By integrating (60), this is equivalent to defining $x_{0}$ and $x_{5}$ as solutions to

$$
\int_{x_{0}}^{x_{5}} \frac{\Pi(\xi)}{\xi^{\gamma_{B}+1}} \mathrm{~d} \xi=0 \text { and } \quad \int_{x_{0}}^{x_{5}} \frac{\Pi(\xi)}{\xi^{\gamma_{A}+1}} \mathrm{~d} \xi=0 .
$$

We now state conditions to solve (61). We first assume that ${ }^{12}$

$$
\int_{x_{1}}^{x_{4}} \frac{\Pi(\xi)}{\xi^{\gamma_{B}+1}} \mathrm{~d} \xi=\int_{x_{3}}^{x_{4}} \frac{\Pi(\xi)}{\xi^{\gamma_{B}+1}} \mathrm{~d} \xi>0
$$

We may then define the term

$$
x_{\dagger}:=\inf \left\{0<z<x_{1} \mid \int_{z}^{x_{4}} \frac{\Pi(\xi)}{\xi^{\gamma_{B}+1}} \mathrm{~d} \xi>0\right\} .
$$

We may have $x_{\dagger}=0$; if it is not the case, we define $0<x_{\dagger}<x_{1}$ as the solution to $\int_{x_{\dagger}}^{x_{4}} \Pi(\xi) \xi^{-\gamma_{B}-1} \mathrm{~d} \xi=0$.

For a given $u \in\left(x_{\dagger}, x_{1}\right)$, the function $v \mapsto \int_{u}^{v} \frac{\Pi(z)}{z^{\gamma} B^{+1}} \mathrm{~d} z$ is monotone decreasing on its domain of definition $\left[x_{4}, \infty\right)$ from a strictly positive amount to $-\infty$. This function therefore admits a unique root $v(u)$ in $\left[x_{4}, \infty\right)$, satisfying

$$
\int_{u}^{v(u)} \frac{g(\xi)}{\xi^{\gamma_{B}+1}} \mathrm{~d} \xi=0
$$

We understand the mapping $u \mapsto v(u)$ as a function from $\left(x_{\dagger}, x_{1}\right)$ to $\left[x_{4}, \infty\right)$. By the chain's rule,

$$
v^{\prime}(u)=\frac{\Pi(u)}{\Pi(v(u))}\left(\frac{v(u)}{u}\right)^{\gamma_{B}+1}
$$

It follows from $u<x_{1}\left(\right.$ resp. $\left.v(u)>x_{4}\right)$ that $\Pi(u)<0$ (resp. $\left.\Pi(v(u))<0\right)$; hence, the function $v(\cdot)$ is monotone increasing.

\footnotetext{
${ }^{12}$ We could not specify the sign of $\Pi(x, \delta)$ in $\left(x_{3}(\delta), x_{4}(\delta)\right)$. We instead made an assumption in ?? that, in probabilistic terms, allows an episode when the firm incurs an economic loss $\left[\Pi\left(X_{t}, \delta\right)<0\right]$ as long as the present value is positive when profitability $\left(X_{t} ; t \geq 0\right)$ remains in the range $\left(x_{3}(\delta), x_{4}(\delta)\right)$. The condition $\Pi(x, \delta)>0$ for all $x \in\left(x_{3}(\delta), x_{4}(\delta)\right)$ is stronger and subsumed into our assumption.
} 
We next define the function

$$
G(u):=\int_{u}^{v(u)} \frac{\Pi(\xi)}{\xi^{\gamma_{A}+1}} \mathrm{~d} \xi
$$

We can compute:

$$
G^{\prime}(u)=\frac{\Pi(u)}{u^{\gamma_{A}+1}}\left[\left(\frac{v(u)}{u}\right)^{\gamma_{B}-\gamma_{A}}-1\right]
$$

Because $\Pi(u)<0$ and $v(u)>u$, it obtains that $G^{\prime}(u)>0$. Consequently, the function $G(\cdot)$ is monotone increasing on its domain $\left(x_{\dagger}, x_{1}\right)$. For this function to have a unique root, it is necessary and sufficient that

$$
G\left(x_{\dagger}\right)<0 \quad \text { and } \quad G\left(x_{1}\right)>0 .
$$

If $x_{\dagger}=0$, then the first assumption $G(a)<0$ is satisfied because $G(0)=-\infty$.

The above ensures the existence and uniqueness of solutions $x_{0}$ and $x_{5}$ to the equations (61). We can then state the solution to the FBP (58a)-(58c) is continuously differentiable and given by (45).

Optimality. It remains to prove that

$$
\begin{aligned}
\chi(x) & \geq 0, \\
\mathcal{L} \chi(x) & \geq \Pi(x), \quad x \in\left(0, x_{0}\right) \cup\left(x_{0}, x_{5}\right)
\end{aligned}
$$

for $C^{1}$ solution $\chi$ of the FBP (58a)-(58c) to solve the VI (43). Proving (66b) is immediate because $\chi(x)=0$ and $\Pi(x)<0$ in the stopping regions. To prove (66a) we consider subregions in turn:

a) $\underline{\left(x_{0}, x_{3}\right)}$. It follows from $(58 \mathrm{~b})-(58 \mathrm{c})$ that

$$
\mathcal{L} \chi\left(x_{0}+\right)=-\frac{1}{2} \sigma^{2} x_{0}^{2} \chi^{\prime \prime}\left(x_{0}+\right)
$$

Because $\mathcal{L} \chi\left(x_{0}+\right)=\Pi\left(x_{0}\right)<0$, it follows that $\chi^{\prime \prime}\left(x_{0}+\right)>0$. Therefore, for $\varepsilon$ sufficiently small, $\chi^{\prime \prime}\left(x_{0}+t u \varepsilon\right)>0$ with $t, u \in(0,1)$. If we integrate $u \mapsto \chi^{\prime \prime}\left(x_{0}+t u \varepsilon\right)$ and then $t \mapsto \chi^{\prime}\left(x_{0}+t \varepsilon\right)$ on the interval $[0,1]$, then we obtain

$$
\chi\left(x_{0}+\varepsilon\right)=\varepsilon^{2} \int_{0}^{1} \int_{0}^{1} t \chi^{\prime \prime}\left(x_{0}+t u \varepsilon\right) \mathrm{d} t \mathrm{~d} u, \quad \varepsilon>0
$$


because of $(58 \mathrm{c})-(58 \mathrm{c})$. Consequently, $\chi\left(x_{0}+\right)>0$. Necessarily, the function $\chi(\cdot)$ has positive local maxima in $\left(x_{0}, x_{5}\right)$, possibly a maximum. At a local maximum $z$, we necessarily have $\mathcal{L} \chi(z)>0$. Because $\mathcal{L} \chi(x)=\Pi(x) \leq 0$ in $\left(x_{0}, x_{3}\right)$, it follows from the maximum principle that there is no local maximum in $\left(x_{0}, x_{3}\right)$. Therefore, $\chi(\cdot)$ increases on $\left(x_{0}, x_{3}\right)$ taking positive values; in particular, $\chi\left(x_{3}\right)>0$.

b) In the case $\underline{\left(x_{4}, x_{5}\right)}$, we follow a reasoning similar to a). We have

$$
\chi\left(x_{5}-\varepsilon\right)=\varepsilon^{2} \int_{0}^{1} \int_{0}^{1} t \chi^{\prime \prime}\left(x_{5}-t u \varepsilon\right) \mathrm{d} t \mathrm{~d} u, \quad \varepsilon>0 .
$$

We proceed similarly obtaining that $\chi\left(x_{5}-\right)>0$. Because $\mathcal{L} \chi(x)=\Pi(x)<0$ on $\left(x_{4}, x_{5}\right)$, it follows from the maximum principle that there is no local maximum in $\left(x_{4}, x_{5}\right)$. Consequently, $\chi(\cdot)$ decreases on $\left(x_{4}, x_{5}\right)$ taking positive values and $\chi\left(x_{4}\right)>0$.

c) The function $\chi(\cdot)$ on $\left(x_{3}, x_{4}\right)$ solves $\mathcal{L} \chi(x)=\Pi(x)$ with boundary conditions $\chi\left(x_{3}\right)>0$ and $\chi\left(x_{4}\right)>0$. We assume that

$$
\begin{aligned}
& \text { the solution on }\left(x_{3}, x_{4}\right) \text { of } \mathcal{L} \Gamma(x)=\Pi(x) \text { with boundary } \\
& \text { conditions } \Gamma\left(x_{3}\right)=0 \text { and } \Gamma\left(x_{4}\right)=0 \text { is strictly positive. }
\end{aligned}
$$

It is immediate that $\chi(x)>\Gamma(x)$ on $\left(x_{3}, x_{4}\right)$ and, under the assumption $(67)$, that $\chi(x)>0$ on $\left(x_{3}, x_{4}\right)$.

We conclude:

Theorem (Solution of the VI for $\delta \geq \delta^{\star}$ for $\gamma_{A}>2$.). Assume that $\Pi(\cdot)$ satisfies (62). We define $x_{\dagger}$ and $G(\cdot)$ in (63) and (64) respectively. We make the assumptions (65) and (67). Then, $x_{0}$ and $x_{5}$ solve equation (61) uniquely and satisfy (57). Besides, the function $\chi$ given in (45) is a $C^{1}$ solution of the FBP (58a)-(58c) and of the VI (43).

We again omit the verification theorem, leveraging on the known connection between the solution to a VI and the value function of optimal stopping (see Bensoussan and Lions, 1982). 


\section{E Value of debt}

The functional representation of the function $D(\cdot)$ defined in $(4)$ is that of the solution $D(\cdot)$ to the Dirichlet problem:

$$
\begin{aligned}
D\left(x_{0}\right) & =(1-\alpha) \frac{x_{0} \sqrt{\delta}}{r-\mu} \\
\mathcal{L} D(x) & =\beta_{0}-\beta_{1} x \sqrt{\delta} \\
\mathcal{L} D(x) & =\beta_{0}-\beta_{1} x \sqrt{\delta_{3}(x)} \\
\lim _{x \uparrow \infty} \frac{D(x)}{x^{2}} & =\text { constant }>0
\end{aligned}
$$

We assume continuity at $x_{0}$ and $x_{5}$.

We conjecture the solutions

$$
\begin{array}{lll}
D(x)=a(x) x^{\gamma_{A}}+b(x) x^{\gamma_{B}} \text { with } & a^{\prime}(x) x^{\gamma_{A}}+b^{\prime}(x) x^{\gamma_{B}} \equiv 0 & \text { for (68b) } \\
D(x)=a_{\star}(x) x^{\gamma_{A}}+b_{\star}(x) x^{\gamma_{B}} \text { with } & a_{\star}^{\prime}(x) x^{\gamma_{A}}+b_{\star}^{\prime}(x) x^{\gamma_{B}} \equiv 0 & \text { for (68c) }
\end{array}
$$

It follows respectively from (68b) and (68c) that

$$
\begin{array}{lr}
a^{\prime}(x)=-\frac{2}{\left(\gamma_{A}-\gamma_{B}\right) \sigma^{2}} \frac{\beta_{0}-\beta_{1} x \sqrt{\delta}}{x^{\gamma_{A}+1}} & b^{\prime}(x)=\frac{2}{\left(\gamma_{A}-\gamma_{B}\right) \sigma^{2}} \frac{\beta_{0}-\beta_{1} x \sqrt{\delta}}{x^{\gamma_{B}+1}} \\
a_{\star}^{\prime}(x)=-\frac{2}{\left(\gamma_{A}-\gamma_{B}\right) \sigma^{2}} \frac{\beta_{0}-\beta_{1} x \sqrt{\delta_{3}(x)}}{x^{\gamma_{A}+1}} & b_{\star}^{\prime}(x)=\frac{2}{\left(\gamma_{A}-\gamma_{B}\right) \sigma^{2}} \frac{\beta_{0}-\beta_{1} x \sqrt{\delta_{3}(x)}}{x^{\gamma_{B}+1}}
\end{array}
$$

It follows by integration and from continuity at $x_{5}$ that

$$
\begin{array}{lrl}
a_{\star}(x)=\frac{2}{\left(\gamma_{A}-\gamma_{B}\right) \sigma^{2}} \int_{x}^{\infty} \frac{\beta_{0}-\beta_{1} z \sqrt{\delta_{3}(z)}}{z^{\gamma_{A}+1}} \mathrm{~d} z & x \geq x_{5}, \\
a(x)=\frac{2}{\left(\gamma_{A}-\gamma_{B}\right) \sigma^{2}}\left[\int_{x}^{x_{5}} \frac{\beta_{0}-\beta_{1} z \sqrt{\delta}}{z^{\gamma_{A}+1}} \mathrm{~d} z+\int_{x_{5}}^{\infty} \frac{\beta_{0}-\beta_{1} z \sqrt{\delta_{3}(z)}}{z^{\gamma_{A}+1}} \mathrm{~d} z\right], & x_{0}<x<x_{5} \\
b(x)=b\left(x_{0}\right)+\frac{2}{\left(\gamma_{A}-\gamma_{B}\right) \sigma^{2}} \int_{x_{0}}^{x} \frac{\beta_{0}-\beta_{1} z \sqrt{\delta}}{z^{\gamma_{B}+1}} \mathrm{~d} z & x_{0}<x<x_{5}, \\
b_{\star}(x)=b\left(x_{0}\right)+\frac{2}{\left(\gamma_{A}-\gamma_{B}\right) \sigma^{2}}\left[\int_{x_{0}}^{x_{5}} \frac{\beta_{0}-\beta_{1} z \sqrt{\delta}}{z^{\gamma_{B}+1}} \mathrm{~d} z+\int_{x_{5}}^{x} \frac{\beta_{0}-\beta_{1} z \sqrt{\delta_{3}(z)}}{z^{\gamma_{B}+1}} \mathrm{~d} z\right] & x \geq x_{5} .
\end{array}
$$


We know that

$$
\frac{x \sqrt{\delta}}{r-\mu}=\frac{2}{\left(\gamma_{A}-\gamma_{B}\right) \sigma^{2}}\left[x^{\gamma_{B}} \int_{0}^{x} \frac{z \sqrt{\delta}}{z^{\gamma_{B}+1}} \mathrm{~d} z+x^{\gamma_{A}} \int_{x}^{\infty} \frac{z \sqrt{\delta}}{z^{\gamma_{A}+1}} \mathrm{~d} z\right]
$$

Therefore, by continuity at $x_{0}$, it must be that

$$
b\left(x_{0}\right)=\frac{2}{\left(\gamma_{A}-\gamma_{B}\right) \sigma^{2}} \int_{0}^{x_{0}} \frac{(1-\alpha) z \sqrt{\delta}}{z^{\gamma_{B}+1}} \mathrm{~d} z .
$$

The expression for $D(x, \delta)$ obtains:

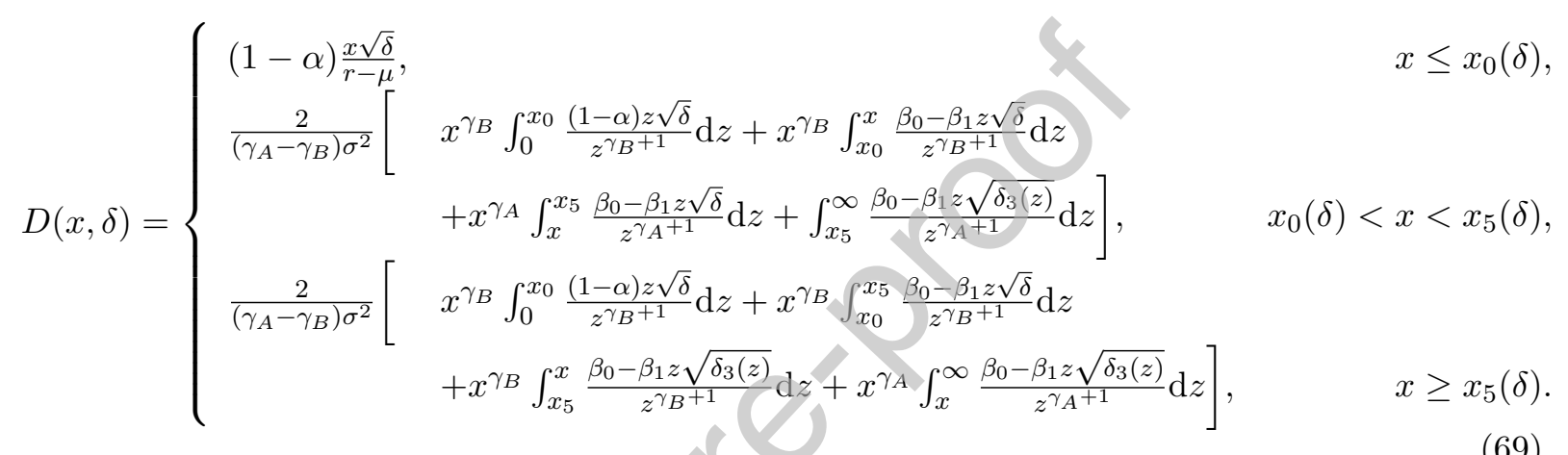

